\title{
Research Paper: Systematic Review on Social Support of Parent/Parents of Disabled Children
}

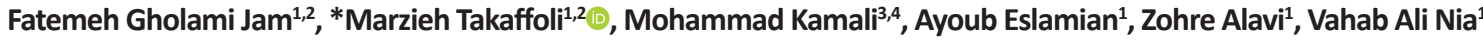

1. Department of Social Work, University of Social Welfare and Rehabilitation Sciences, Tehran, Iran.

2. Student Research Committee, University of Social Welfare and Rehabilitation Sciences, Tehran, Iran.

3. Department of Basic Sciences, School of Rehabilitation Sciences, Iran University of Medical Sciences, Tehran, Iran.

4. Department of Rehabilitation Management, School of Rehabilitation Sciences, Iran University of Medical Sciences, Tehran, Iran.

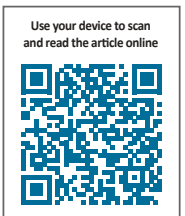

Citation: Gholami Jam F, Takaffoli M, Kamali M, Eslamian A, Alavi Z, Ali Nia V. [Systematic Review on Social Support of Parent/Parents of Disabled Children (Persian)]. Archives of Rehabilitation. 2018; 19(2):126-141. http://dx.doi.org/10.32598/rj.19.2.126

doi): http://dx.doi.org/10.32598/rj.19.2.126

Received: 10 Nov 2017 Accepted: 14 Mar 2018
Keywords:

Disabled child, Par-

ent, Social support,

Systematic review

\section{ABSTRACT}

Objective Parents with a disabled child face many challenges, including the imbalance between work and leisure, limited social life and time limitations. Social support is a multidimensional index that shows the individual's perception of being supported, loved, and valued. Owing to the importance of social support of parents/caregivers of disabled children and its impact on their physical, psychological, social and spiritual aspects, a systematic review was conducted with an aim to assess and summarize the results of the studies already conducted in our country. Materials \& Methods The study population included all the published articles since February 1395, containing quantitative data about the social support of disabled parents from the studies conducted in Iran in Persian. In the first phase, in order to achieve related studies, four categories of related keywords were included: 1=(support, social support), 2=(father, mother, parent, caregiver), 3=(child, girl, son) and 4=(handicapped, disabled, exceptional, patient) to search in the scientific databases of Iranmedex, SID, Magiran, Noormags and Google Scholar. Specialized journals such as Archives of Rehabilitations, Journal of Modern Rehabilitation, Journal of Paramedical Science and Rehabilitation and Journal of Research in Rehabilitation Sciences were also visited to access all articles. In all, 683 studies were obtained, in this phase. In the second phase, according to the title of studies, repetitive and nonrelated subjects were excluded; thus 384 studies remained. Then, considering the inclusion and exclusion criteria, the abstracts of the remaining studies were reviewed. The quality of the methods used to search articles (based on the exact definition of the target group, type of study, sampling method, sample size, validity and reliability of the data gathering tool) were also assessed. Finally, 14 studies remained for the final evaluation. The required data were extracted from the studies according to the table of findings for the qualitative analysis of the data. To increase the validity of the study, each process of search in different databases, initial review of the articles, adaptation to the criteria and investigation of the quality of studies was done by two researchers independently; in case of any disagreement, a consensus was reached with the help of the opinion of a third researcher.

Results Based on the methodologies used and the subsequent findings, all the 14 articles were found to be crosssectional, half of them were correlation studies, and the remaining were causal-comparative studies. In this review, 5 different tools were used for data collection; more than half of the studies (57\%) used the Multidimensional Scale of Perceived Social Support, followed by the Scale of Social Support developed by Vaux et al. (14.2\%). It is noteworthy that majority (64\%) of the studies examined the mother and others considered both parents. Children with intellectual disabilities, such as mental retardation and Down syndrome had the highest (34.48\%) support, followed by children with hearing impairments (17.24\%), physical-movement disorders (17.24\%) and visual impairments (13.79\%). Studies that compared social support between parent/parents of ordinary children with disabled ones showed that there was a significant difference between social protections of the two groups. The relationship between social support and mental health, mindfulness, resilience, life satisfaction, marital satisfaction, psychological well-being, adaptability, stress, stress coping strategies and post-traumatic stress variables have been discussed in these studies.

Conclusion Social support of parents with a disabled child has been addressed more in recent years. The articles on social support of parents examined only the effect of taking care of these children and the decline of it. In fact, they remain largely descriptive and theoretical, and there are no operational strategies to improve social support.

\section{* Corresponding Author:}

Marzieh Takaffoli, PhD Candidate

Address: Department of Social Work, University of Social Welfare and Rehabilitation Sciences, Tehran, Iran.

Tel: +98 (912) 5101115

E-Mail: marzieh.takaffoli@gmail.com 


\title{
مرور نظاممند يثوهشهاى مربوط به حمايت اجتماعى از والد / الدين كودكان داراى معلوليت
}

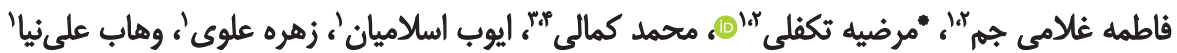

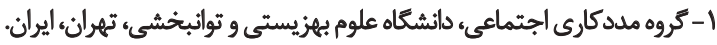

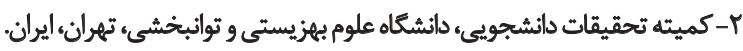

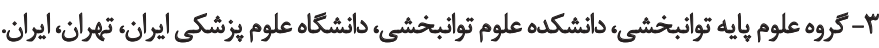

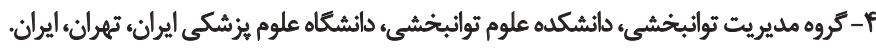

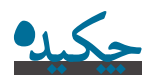

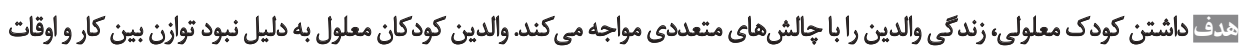

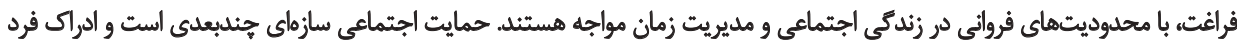

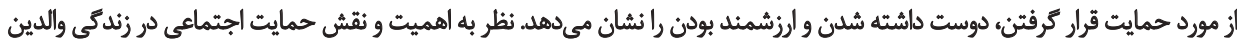

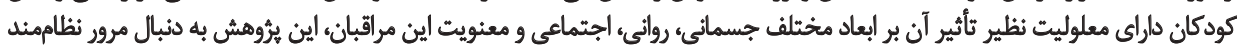

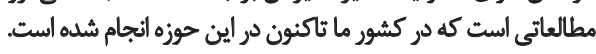

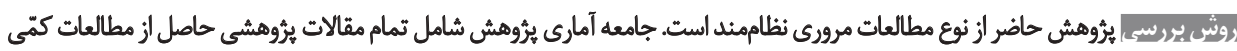

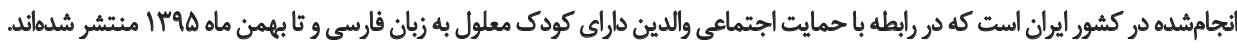

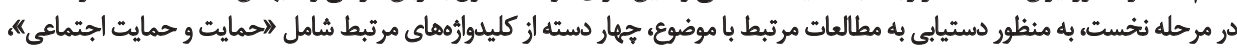

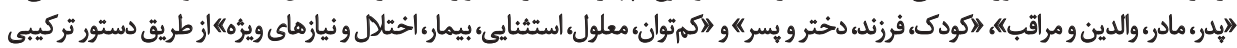

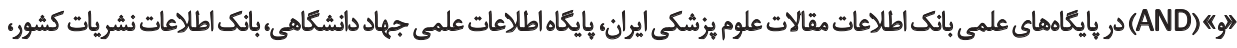

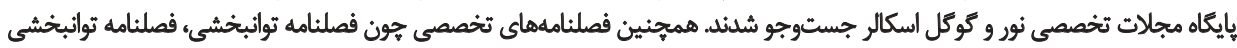

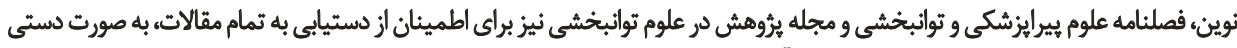

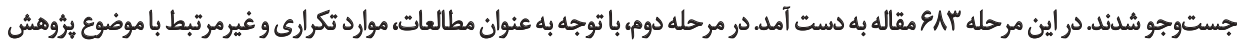

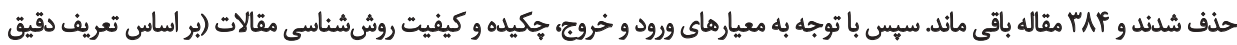

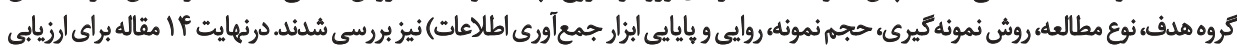

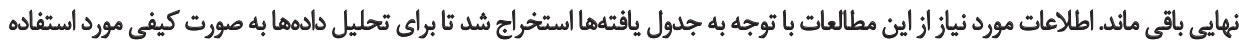

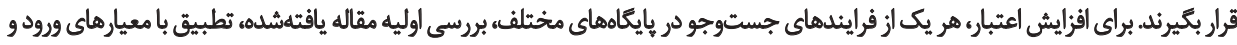

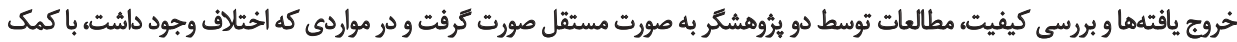

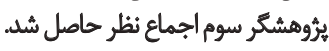

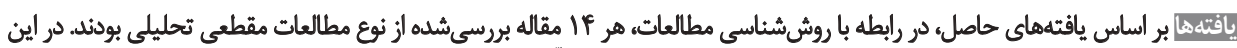

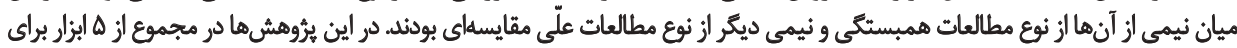

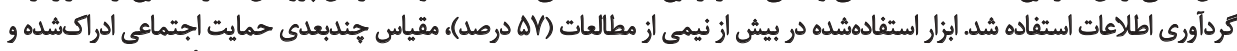

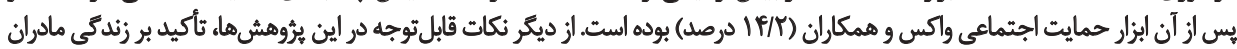

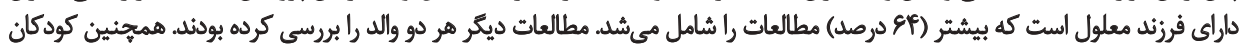

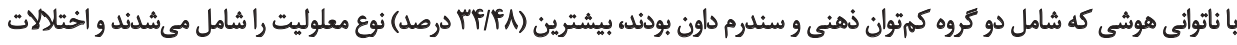

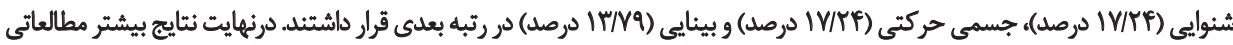

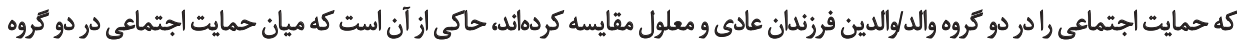

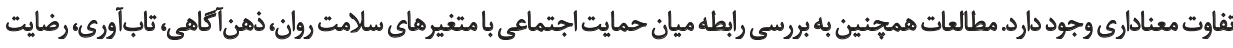

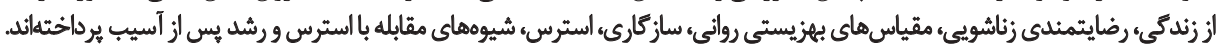

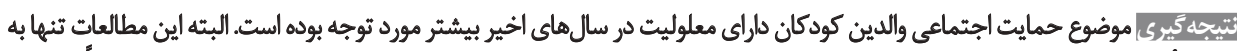

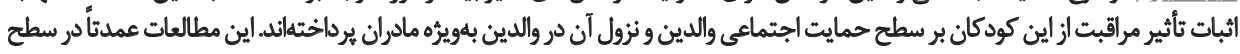

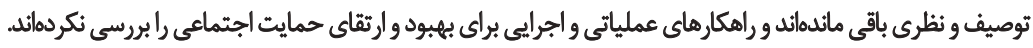

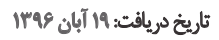

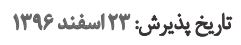

كليدوإوها:

كودى معلول، والد، حمايت اجتماعي، مرور نظاممند

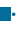

$$
\begin{aligned}
& \text { * نويسينده ميسئول: }
\end{aligned}
$$

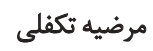

$$
\begin{aligned}
& \text { نشاني: تهران، دائشكاه علوم بهزئيتي و توانبخشي، كروه مدد كاري اجتماعي. } \\
& \text { تلفئ: } \\
& \text { راياثامه: marzieh.takaffoli@gmail.com }
\end{aligned}
$$




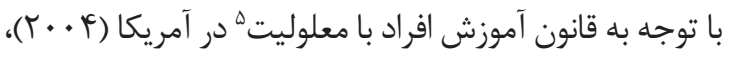

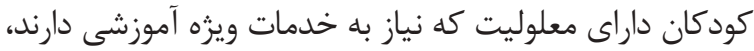

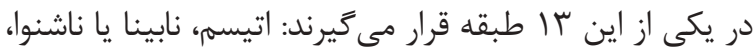

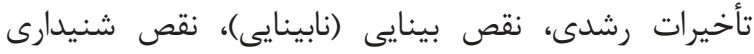

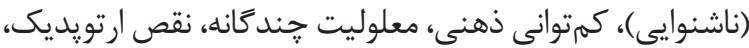

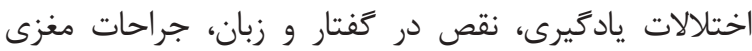

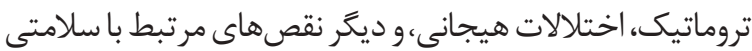

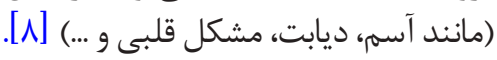
در كشور ما با توجه به طبقدبندى سازمان آموزش و يرورش

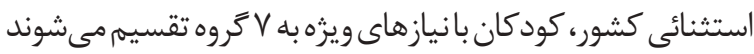

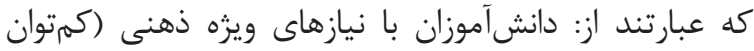

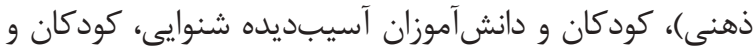

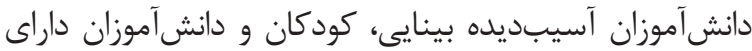

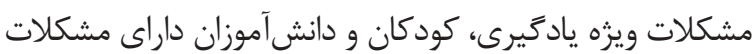

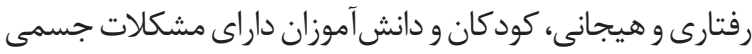

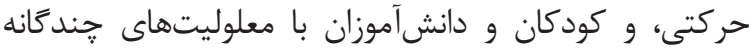

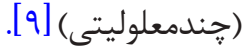

معلوليت نهفقط زندگى فرد را با خالشهايى مواجه مى كند،

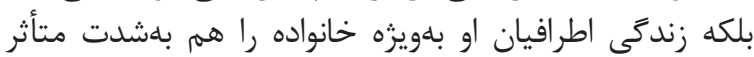

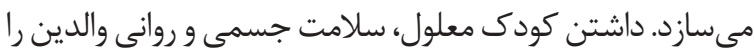

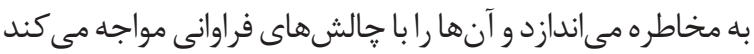

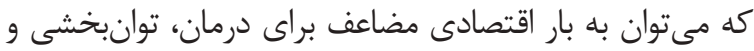

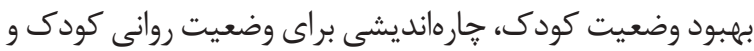

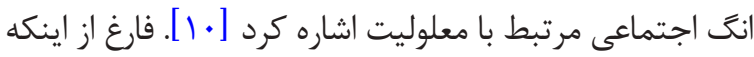

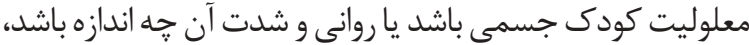

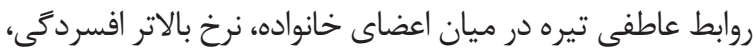

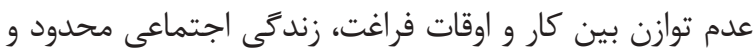

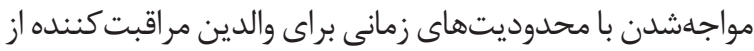

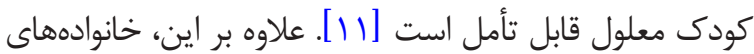

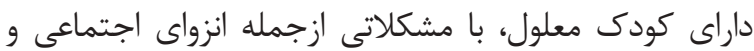

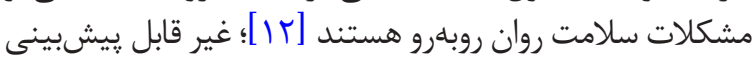

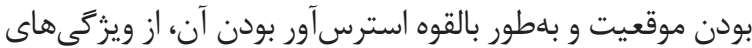

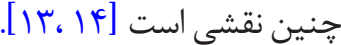

حمايت اجتماعى سازماى جندبعدى است و ادراك فرد از

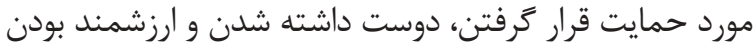

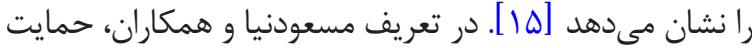

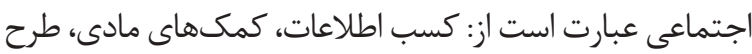

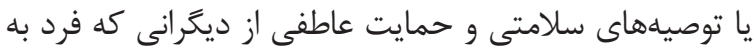

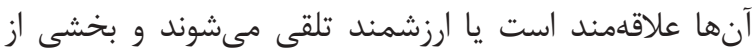

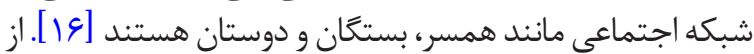
ويزَّى هاى حمايت اجتماعى، تعلق به شبكه اجتماعى و داشتن

\section{Individuals with Disabilities Education Act (IDEA)}

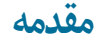

سلامت به معنى برخوردارى از آسايش كامل جسمانى، روانى

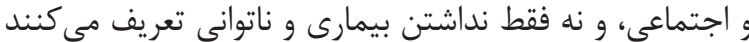

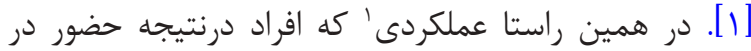

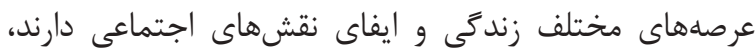

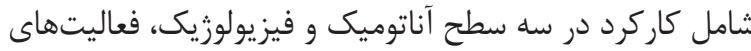

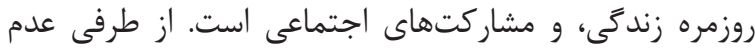

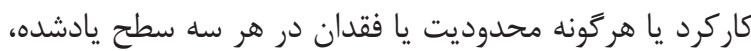

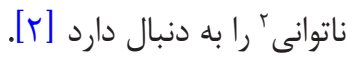

يميامدهاى ناشى از نقص و ناتوانى در زندى إنى اجتماعى افراد،

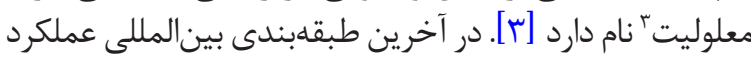

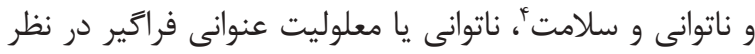

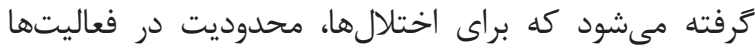

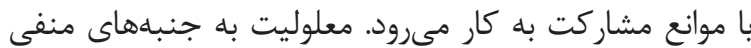

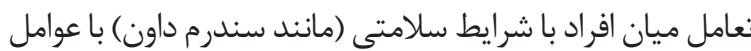

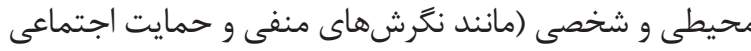

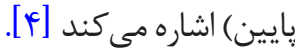

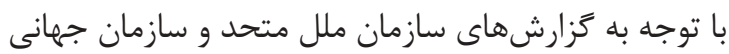

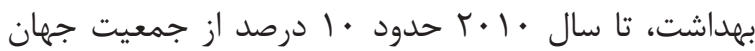

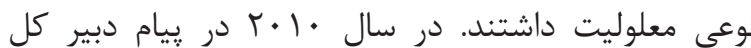

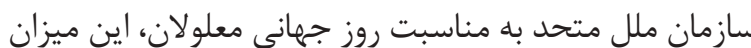

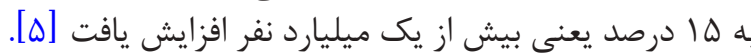

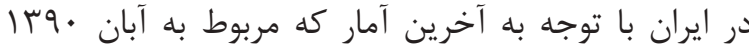

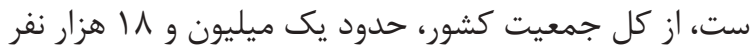

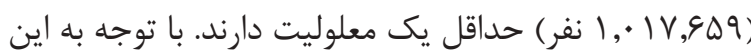

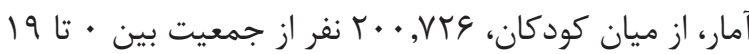

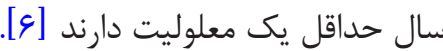
طبقابندى هاى مختلفى براى كود كان معلول وجود دارد كه هر

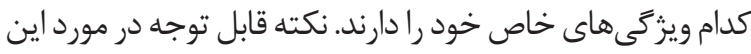

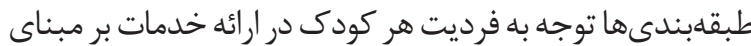

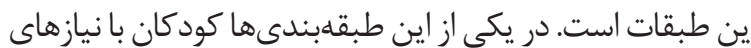

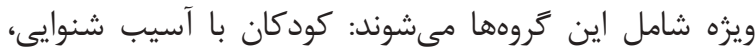

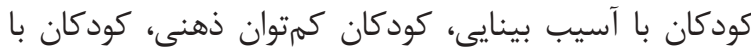

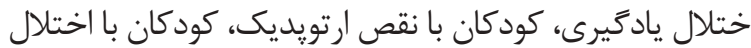

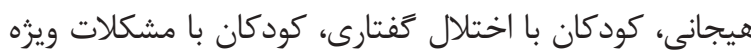

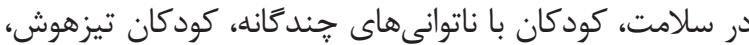

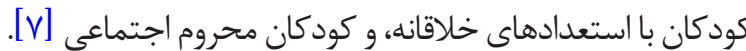

\section{Function}

2. Disability

3. Handicap

4. International Classification of Functioning, Disability and Health (ICF) 


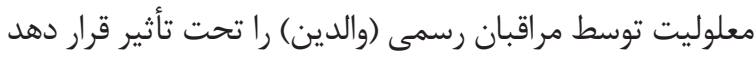

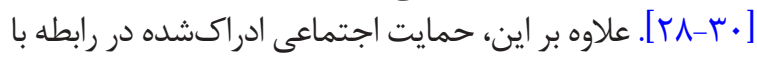

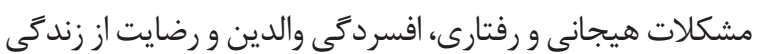

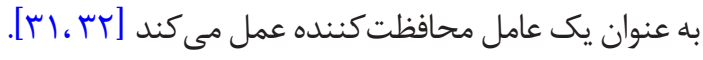
با توجه به آمار قابل توجه معلوليت كودكان در كشور و همجنين

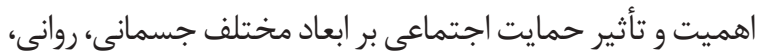

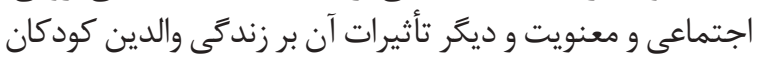

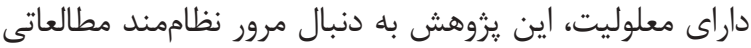

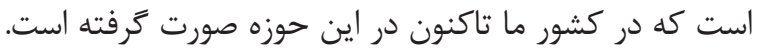

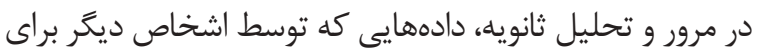

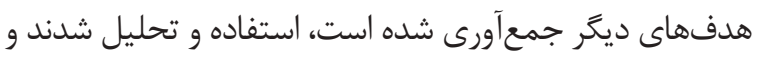

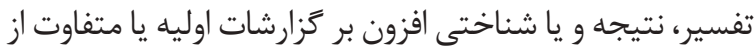

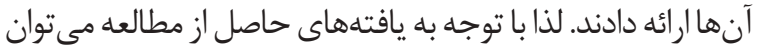

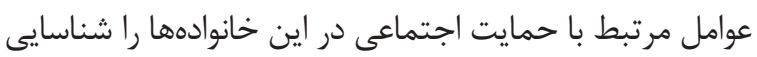

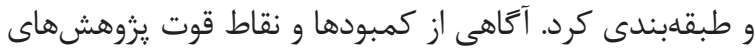

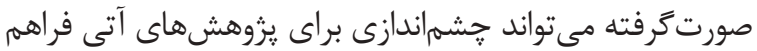

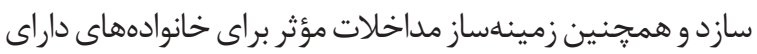

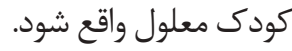

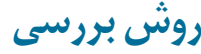

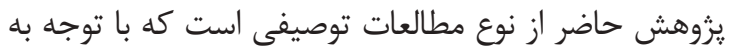

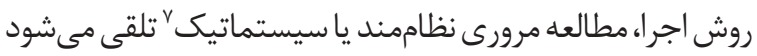

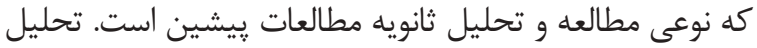

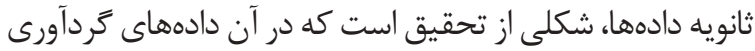

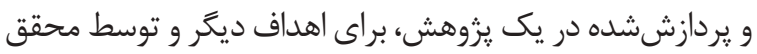

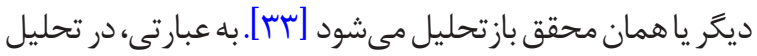

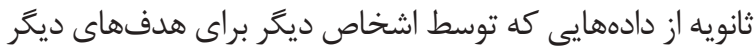

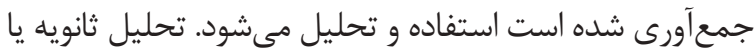

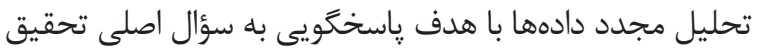

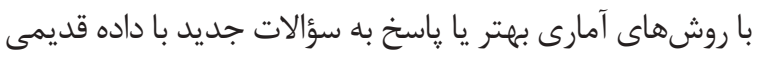

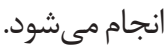

مرور تحقيقات كذشته به شيوههاى مختلفى انجام مى شود كه آنها

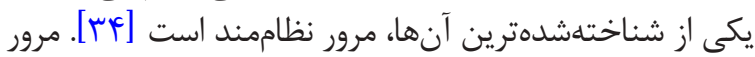

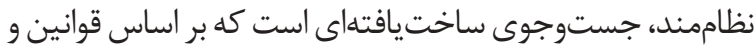

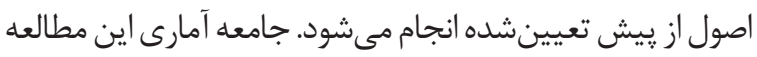

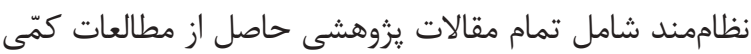

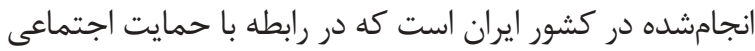

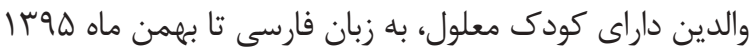

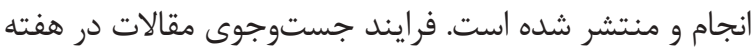
الول اسفند هوبا صورت كرفت.

در مرحله نخست، به منظور دستيابى به مطالعات مرتبط با
تعهدات متقابل نسبت به يكديكر است [IV]

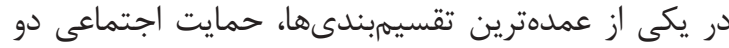

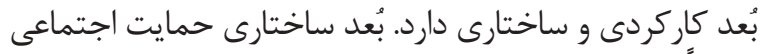

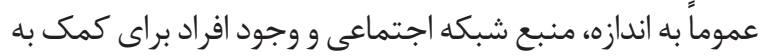

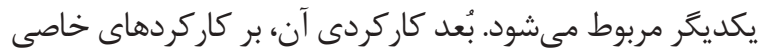

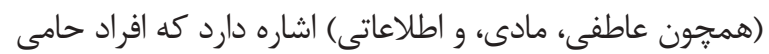

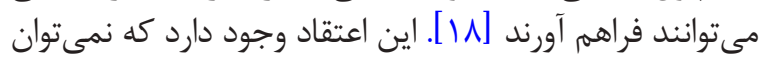

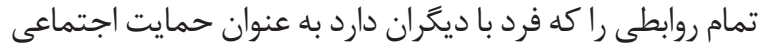

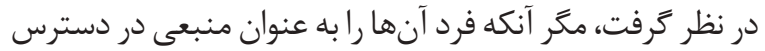

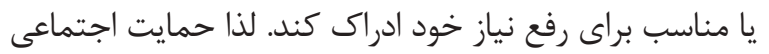

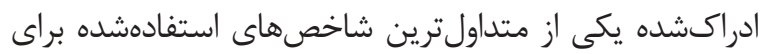

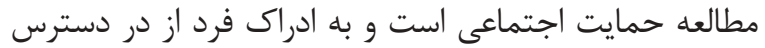

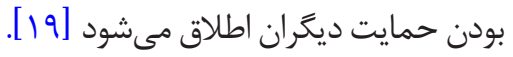
بر اساس مطالعات انجامشده، حمايت اجتماعى به طور معنادارى

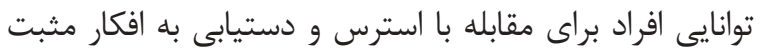

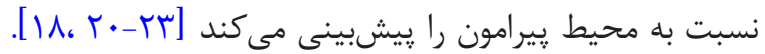

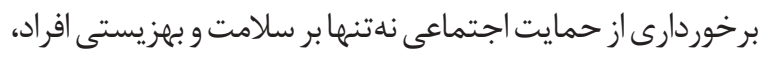

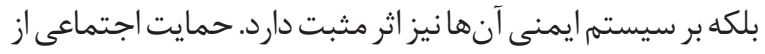

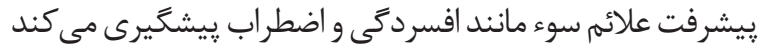

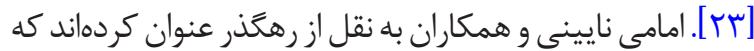

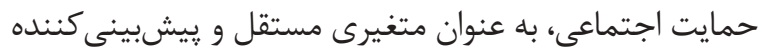

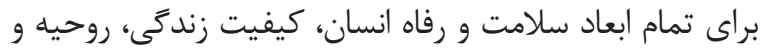

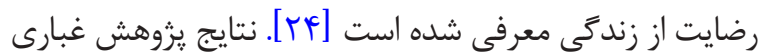

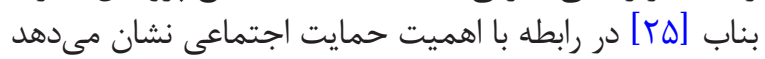

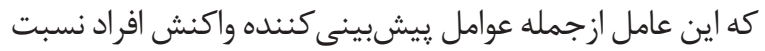

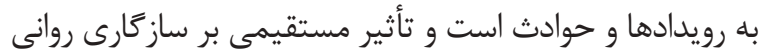

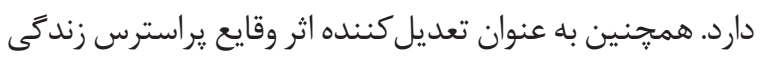

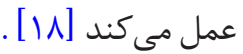
در همين راستا مطالعات متعددى به اهميت حمايت اجتماعى دري

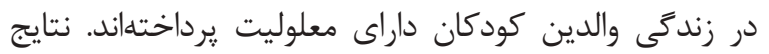

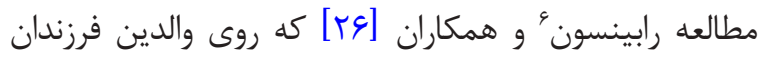

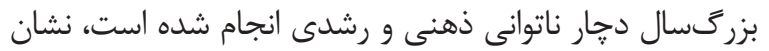

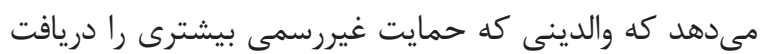

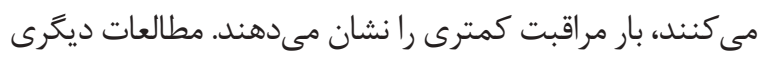

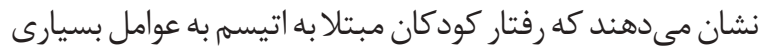

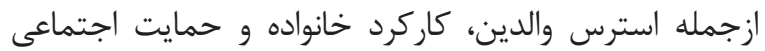

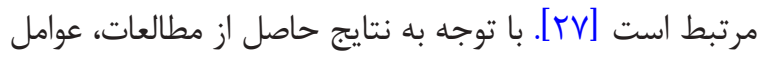

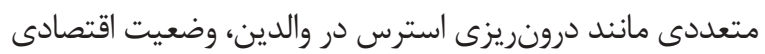

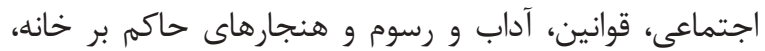

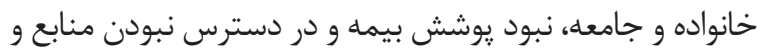

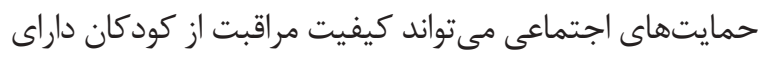


والدين افرادى بالاتر از \\ سال يا والدين كودكان و بزركسالان را

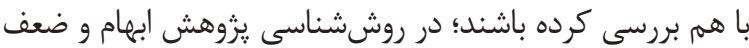

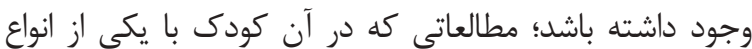

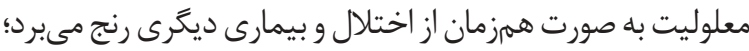

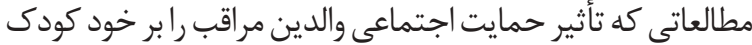

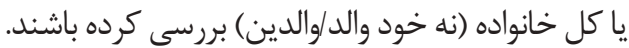

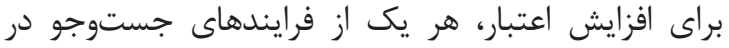

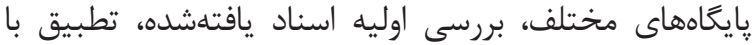

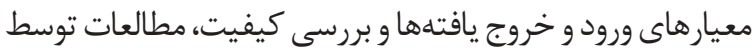

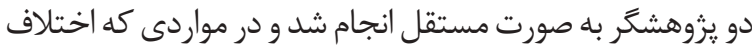

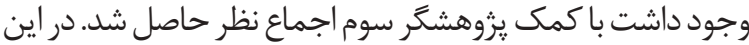

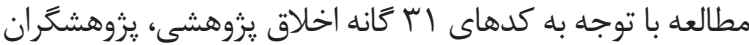

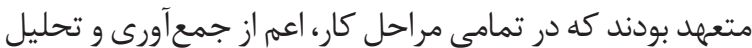

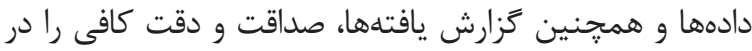

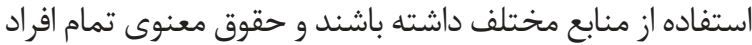

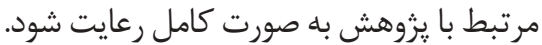

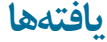

از مجموع مقالات باقى مانده، ff أ مقاله معيارهاى ورود و خروج

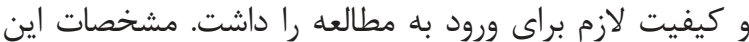

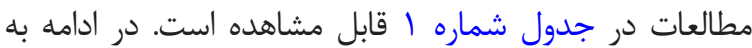

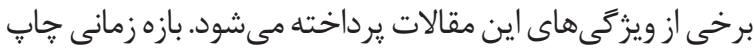

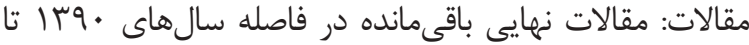

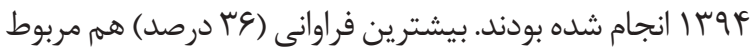

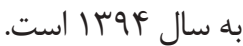

مكان جغرافيايى مطالعات:مكان جغر افيايى مطالعات درشهرهاى

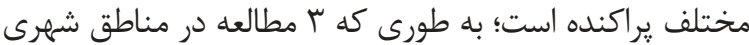

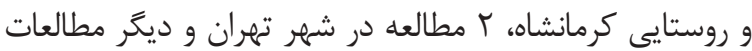

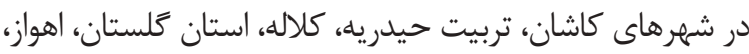
آستارا، اصفهان، بابل، رشت و شير از صورت كرفته بوديت

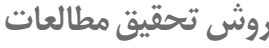

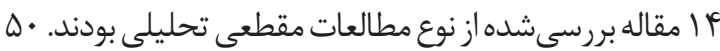

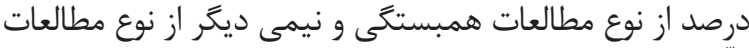

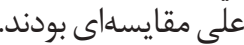

ابزار تر دآورى اطلاعات

در اين يزوهشها درمجموع از ها ابزار براى كردآورى اطلاعات

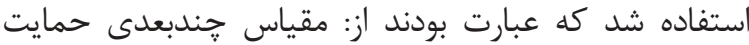
اجتماعى ادراكشده"، مقياس حمايت اجتماعى" واكئ واكس و و
موضوع، جهار دسته از كليدوازههاى مرتبط شامل "حمايت و

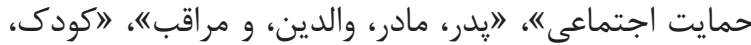

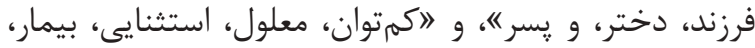

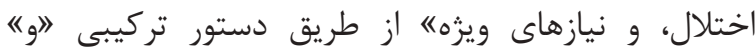

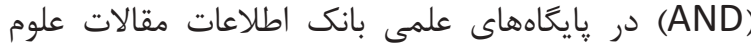

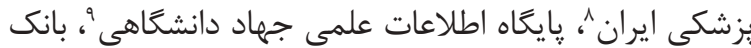

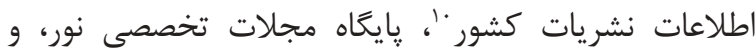
كوزل اسكالر جستوجو شدند. با توجه به محدوديتهاى جستوجو و نبود امكان به كار گيرى

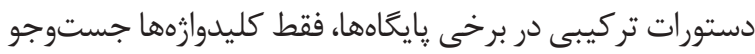

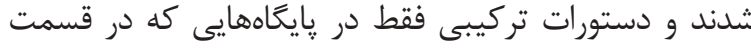

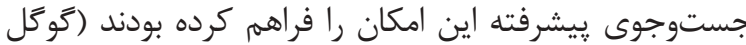

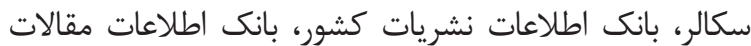

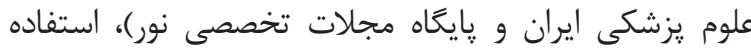

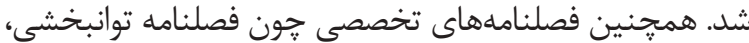

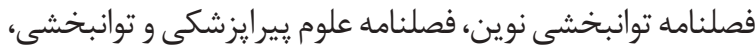

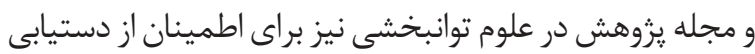

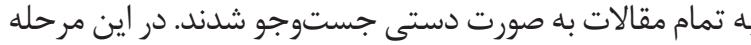

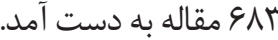

در مرحله دوم، با توجه به عنوان مطالعات، موارد تكرارى و و

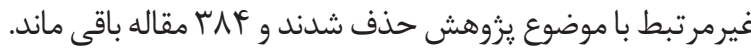

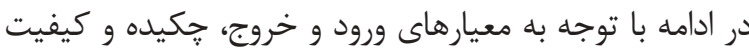
روششناسى مقالات (بر اساس تعريف دقيق ترون

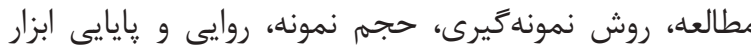

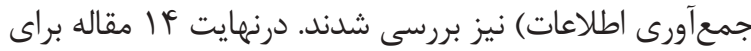

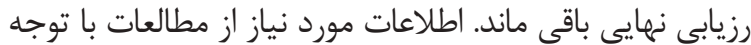

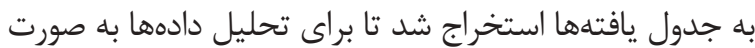

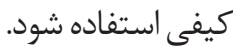

معيارهاى ورود مقالات شامل اين موارد مىشد: موضوع مقاله

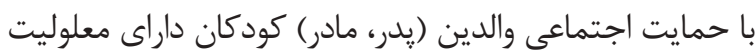

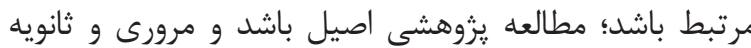

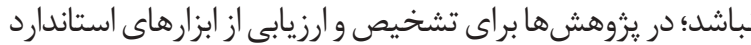

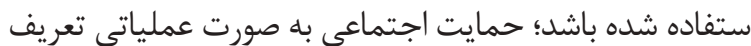

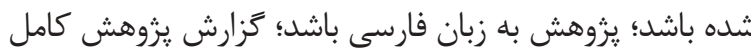

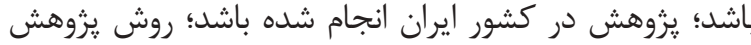

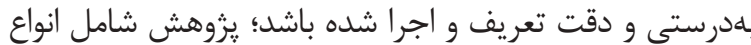

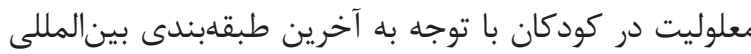

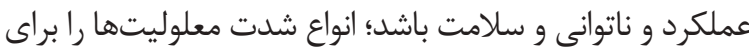
كودكان شامل شود.

معيارهاى خروج مقالات شامل اين موارد مىشد: مقالاتى كه

(Iranmedex) سامانه دانش كستر بركت

9. Scientific Information Database (SID)

10. Magiran 


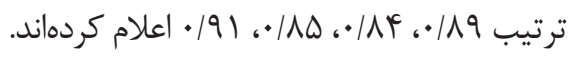

$$
\text { مقياس حمايت اجتماعى واكس و همكاران }
$$

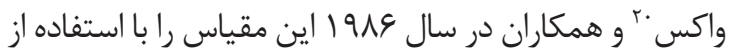
روش تحليل عاملى ساختند. ساختار نظرى اين مقياس بر اساس

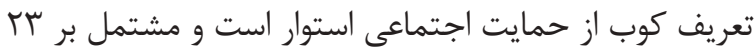

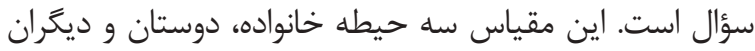

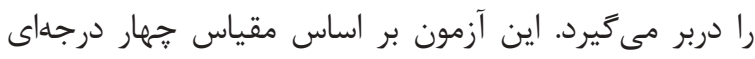

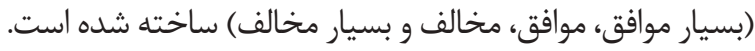

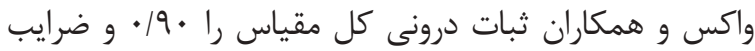

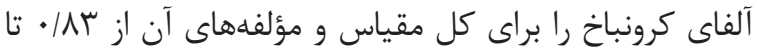

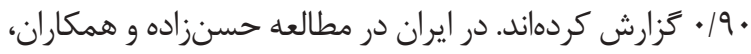

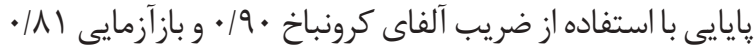

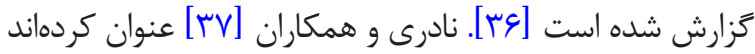

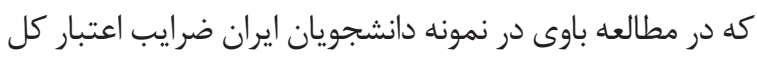

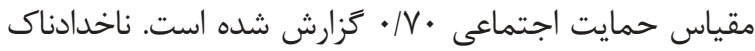

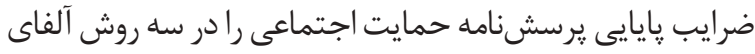

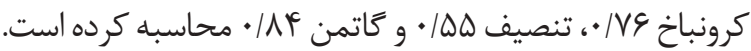

$$
\text { حمايت اجتماعى ادر اكشده فلمينَّ و همكاران }
$$

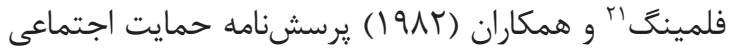

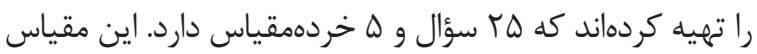

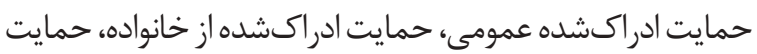
ادراكشده از دوستان، حمايت ادراكشده از همكلاسى هاو آدمات عقيده

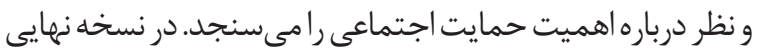
اين مقياس، خردهمقياس مربوط به حمايت دوستان و همسايكان آهميت

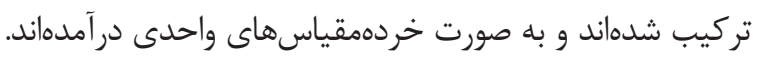

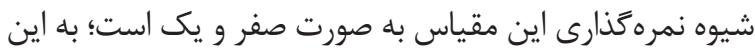

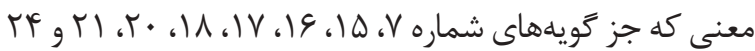

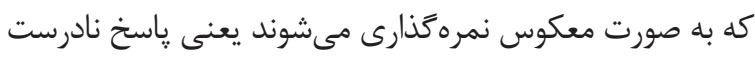

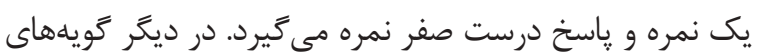

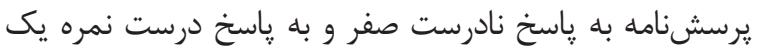

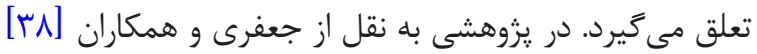

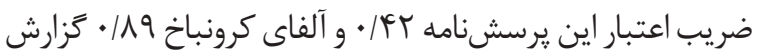

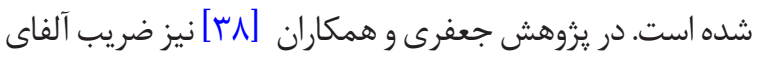

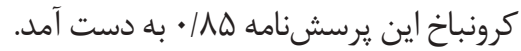

$$
\text { مقياس حمايت اجتماعى نوربك }
$$

اين يرسشنامه را نوربك در سال 1911 تهييه كرد كه ابزار

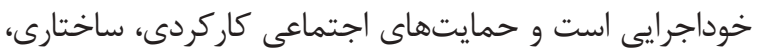
عاطفى، مادى (كمك) و فقدان كل را محاسبه مى كند. علاوه بر اجتر

20. Vaux

21. Fleming
همكاران، حمايت اجتماعى ادراكشده” فلمينت و همكاران،

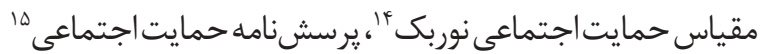

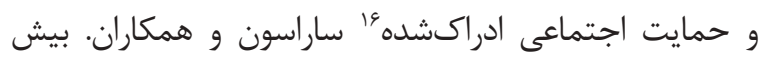

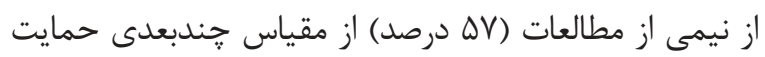

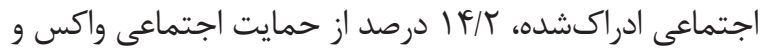

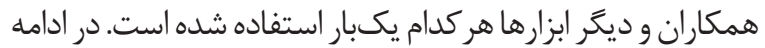

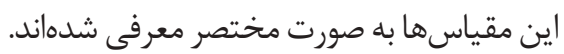
مقياس گتندبعدى حمايت اجتماعى ادر اكشده

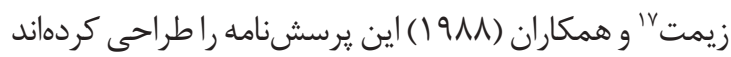

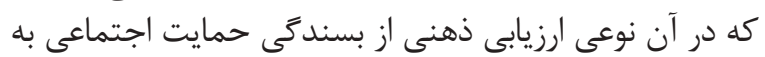

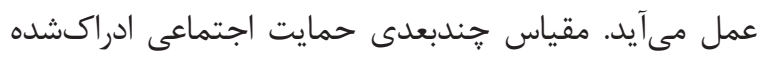

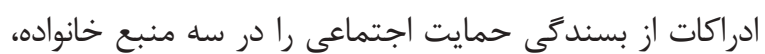

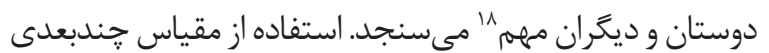

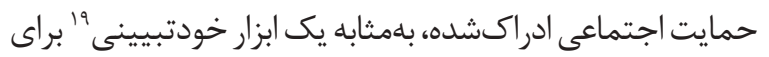

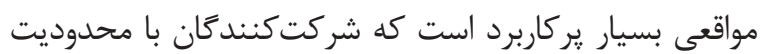

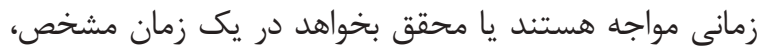

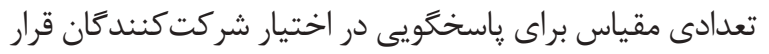

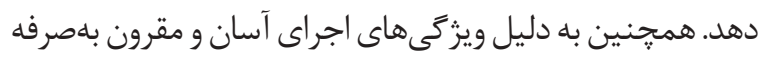
بودن، بلهور مؤكد توصيه شده است.

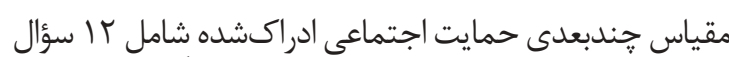

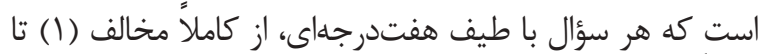

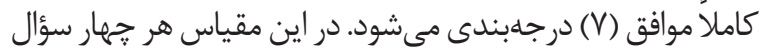

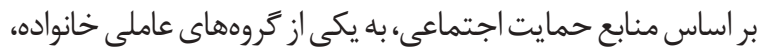

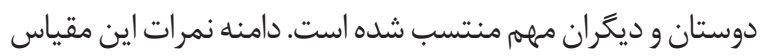

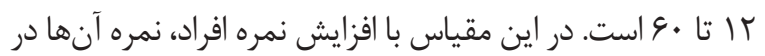

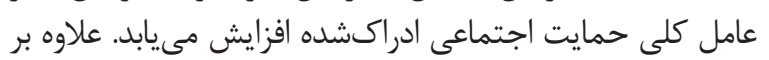

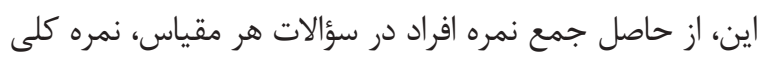

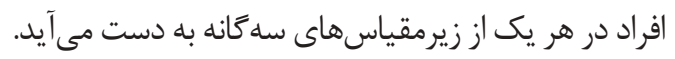
كاكابرايى و همكاران [مس] عنوان كردهاند كه نتايج مطالعه

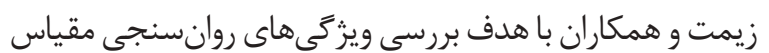

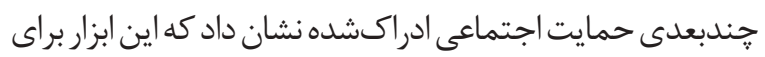
بررسى حمايت اجتماعى ادراكشده روا و و يايا است و سازند إندان

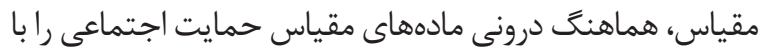

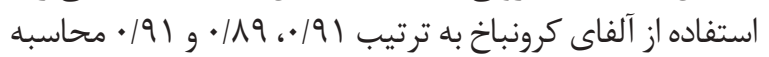

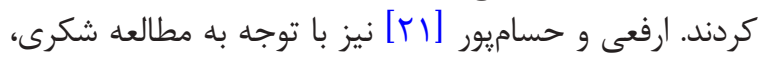

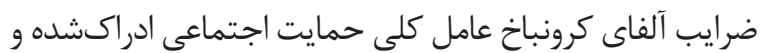

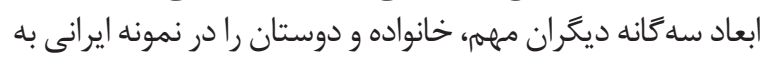

\section{Perceived Social Support Scale}

14. Norbeck Social Support Questionnair (NSSQ)

15. Mos Social Support Scale (MOS-SSS)

16. Social Support Questionnaire

17. Zimet

18. Significant others

19. Self-explanatory 
كه حمايت اجتماعى دريافتشده توسط آزمودنى را مىسنجد.

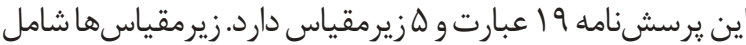

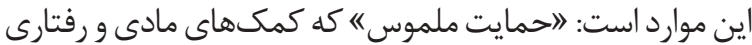

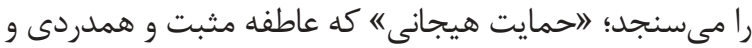

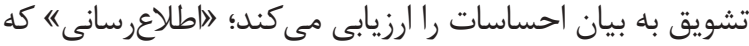

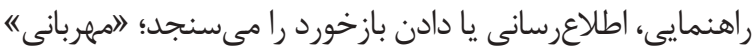

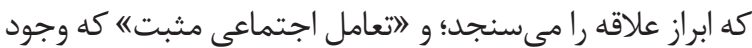

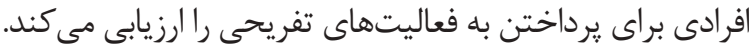

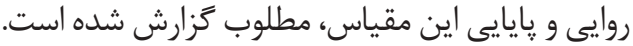

اين مقياس ابزار خودَزارشى است و آزمودنى ميزان مخالفت يا

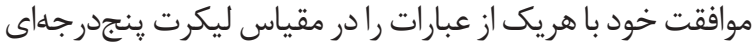

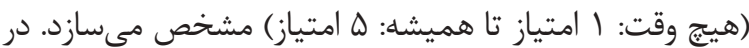

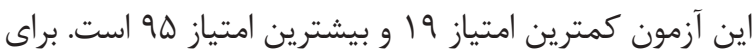

ين موارد، دادههاى توصيفى راجع به ارتباطات حمايتى را كه فرد

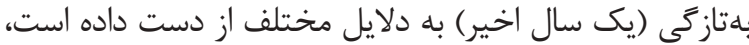

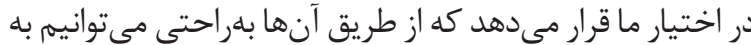

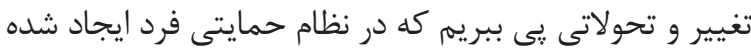

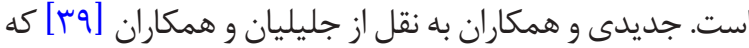

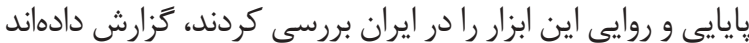

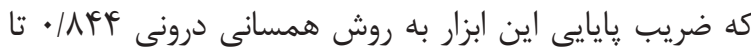

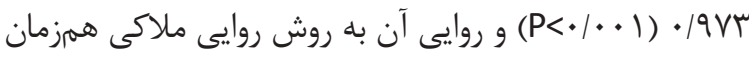

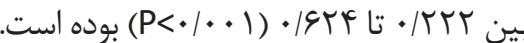

$$
\text { برسش نامه حمايت اجتماعى }
$$

شربورن و استوارت ז' اين مقياس را در سال 199 ساختهاند

\section{Sherbourne \& Stewart}

جدول ا. مشخصات عمومى مقالات منتشرشده در زمينه حمايت اجتماعى والدين كودكان دجار ناتوانى و معلوليت تا سال هوج|

\begin{tabular}{|c|c|c|c|c|c|c|c|c|}
\hline نتيجدكيري مطالعه & إيزار(山) & مطالعه & محل اتجام & ثمونهكيرى & كروه هدف و تعداد & عنوان & سال اتتشار & رديف \\
\hline 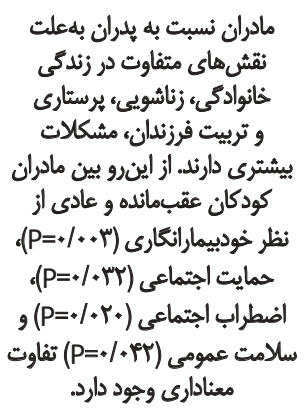 & 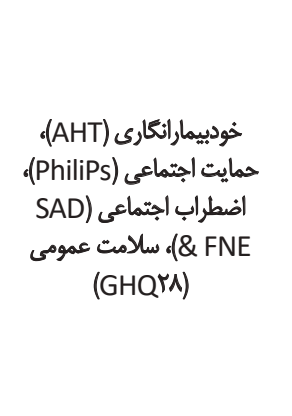 & $\begin{array}{l}\frac{h}{b} \\
\xi^{*} \\
q^{*}\end{array}$ & الهواز & 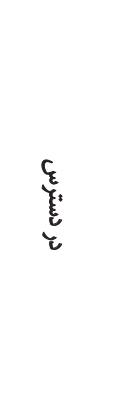 & 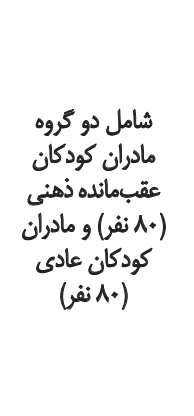 & 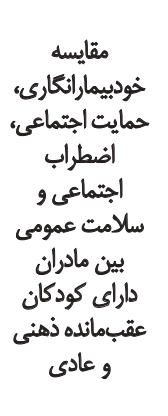 & 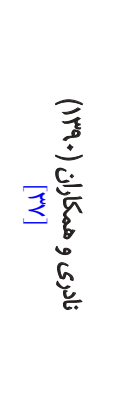 & 1 \\
\hline 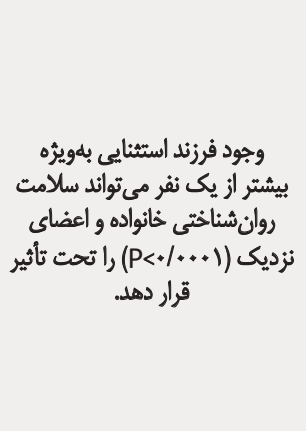 & 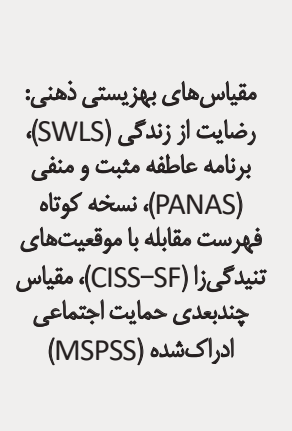 & $\begin{array}{l}\frac{a}{b} \\
\frac{b}{g^{2}} \\
q^{2}\end{array}$ & كرمانشاه & 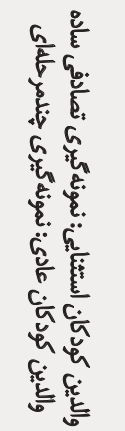 & 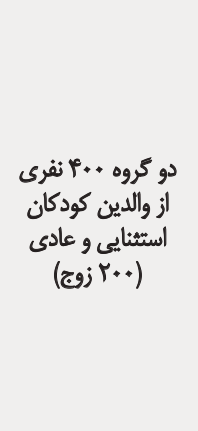 & 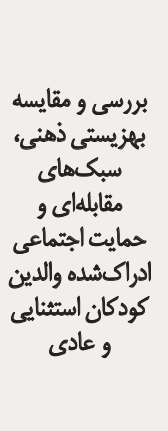 & 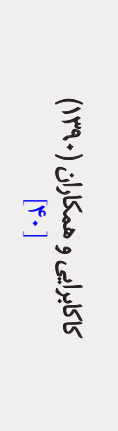 & r \\
\hline 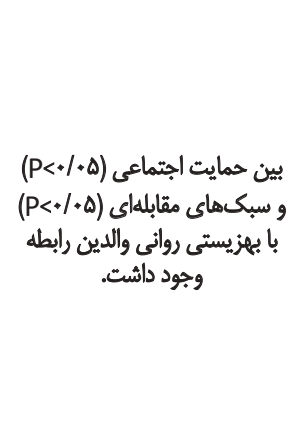 & 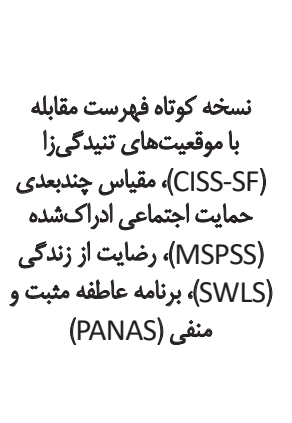 & $\xi$ & كرمانشاه & 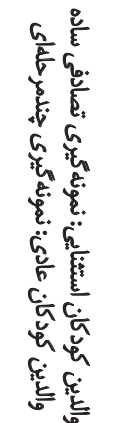 & 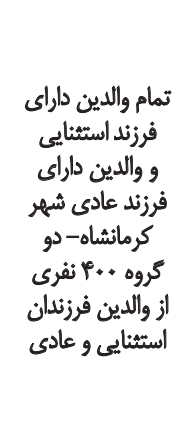 & 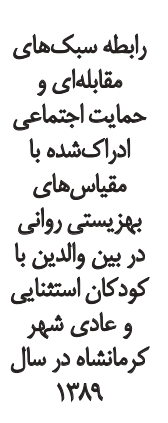 & 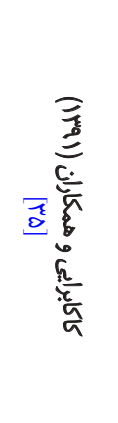 & $r$ \\
\hline
\end{tabular}




\begin{tabular}{|c|c|c|c|c|c|c|c|c|}
\hline نتيجيكيري مطالعه & إبزار|(ه) & مطلعه & محل أنجام & نموندكيرى & كروه هدف و تعداد & عنوان & سال اتتشاري & رديف \\
\hline 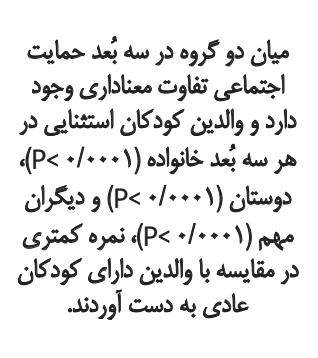 & 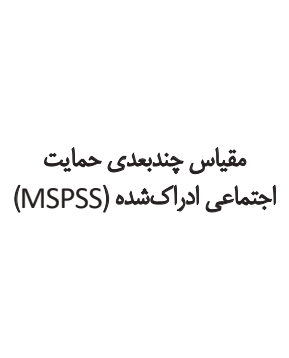 & $\begin{array}{l}\frac{6}{5} \\
\frac{5}{5} \\
b^{2}\end{array}$ & كرماتشاه & 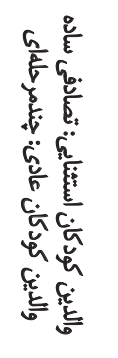 & 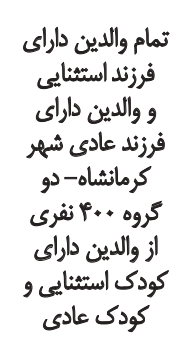 & 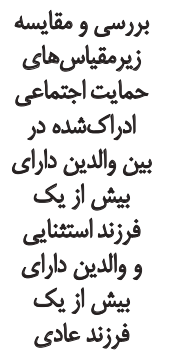 & 全高 & $i$ \\
\hline 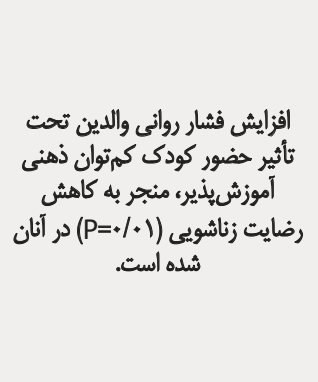 & 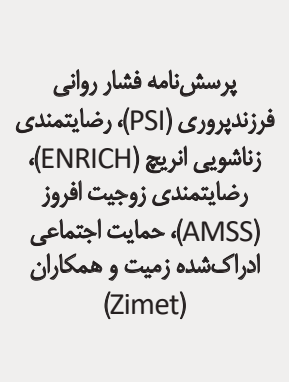 & 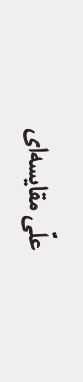 & كلستان & 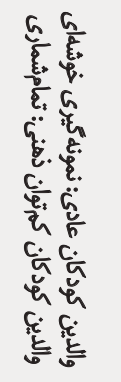 & 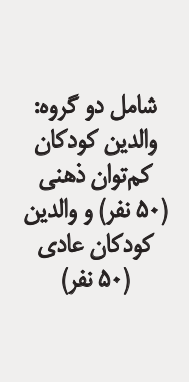 & 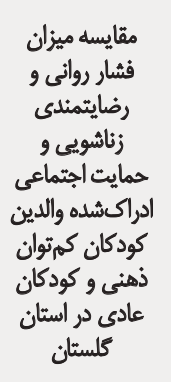 & 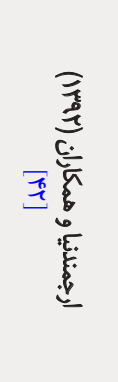 & a \\
\hline 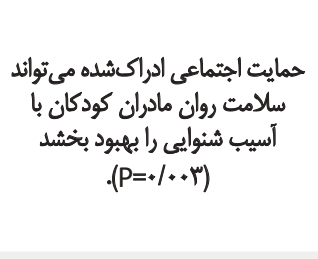 & 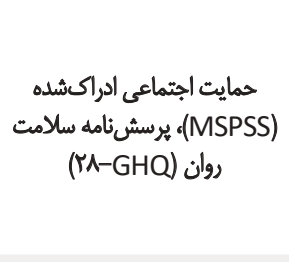 & $\begin{array}{l}\frac{a}{b} \\
\frac{g^{2}}{g^{2}} \\
q^{2}\end{array}$ & بابل & ह & 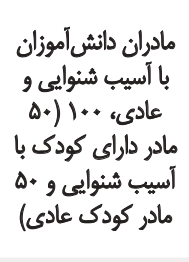 & 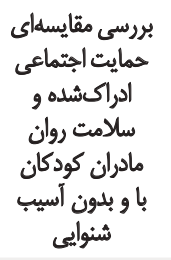 & 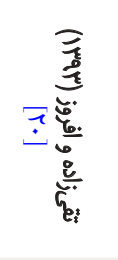 & $\varepsilon$ \\
\hline 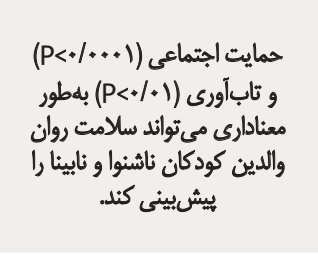 & 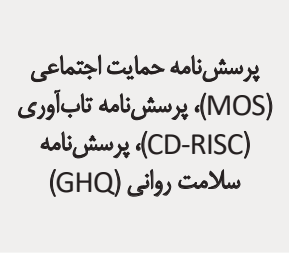 & 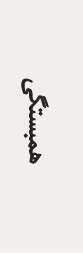 & شيرأز & $\frac{\xi^{8}}{c}$ & 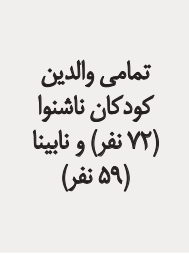 & 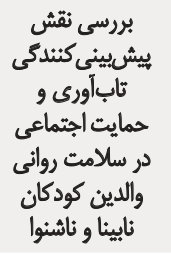 & 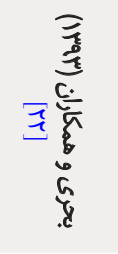 & $r$ \\
\hline 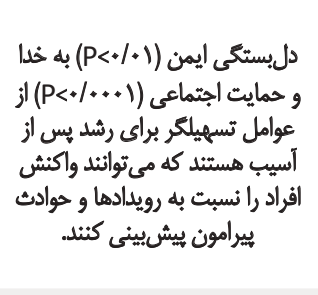 & 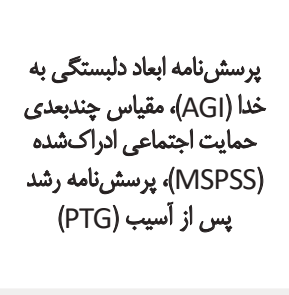 & 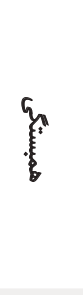 & تيهان & $\underbrace{\varepsilon}_{\mathscr{L}}$ & 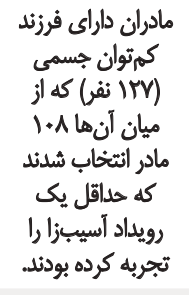 & 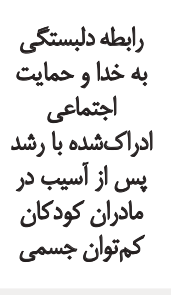 & 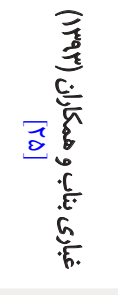 & $\wedge$ \\
\hline 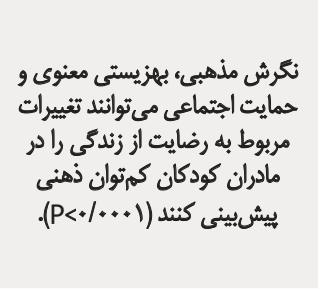 & 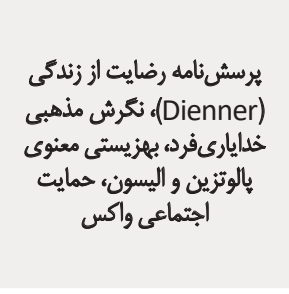 & 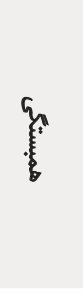 & تربتاميلريه & $\frac{\xi}{\varepsilon}$ & 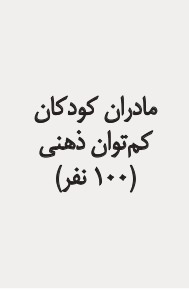 & 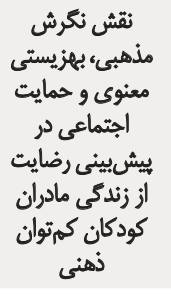 & 委 & 9 \\
\hline 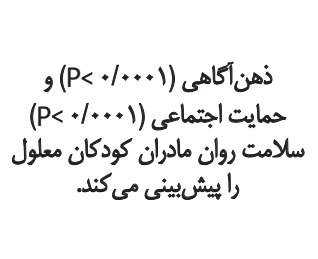 & 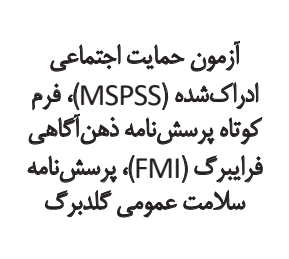 & $\xi$ & كاشان & 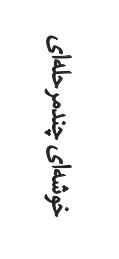 & 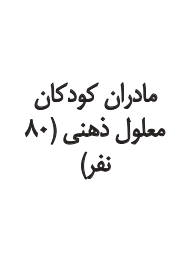 & 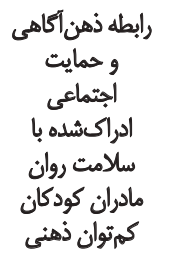 & 衰 & 1. \\
\hline
\end{tabular}




\begin{tabular}{|c|c|c|c|c|c|c|c|c|}
\hline تثيجه كيري مطالعه & ابزار|ر(ه) & مطلعه & محل أجاميم & نمونه ئيرى & كروه هدف و تعداد & عنوان & سال اتتشار & رديف \\
\hline 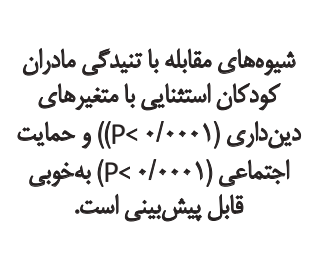 & 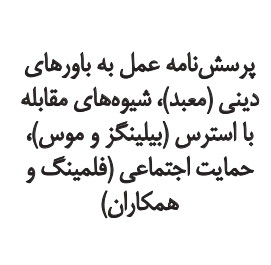 & 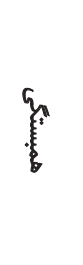 & آستارا & $\underbrace{\varepsilon}_{\check{L}}$ & 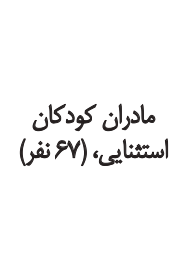 & 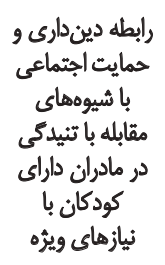 & 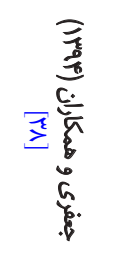 & 11 \\
\hline 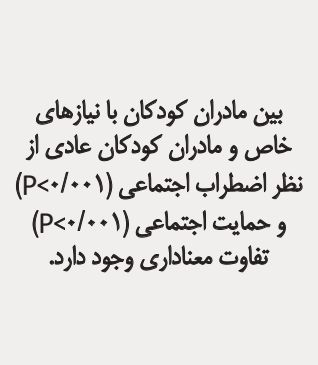 & 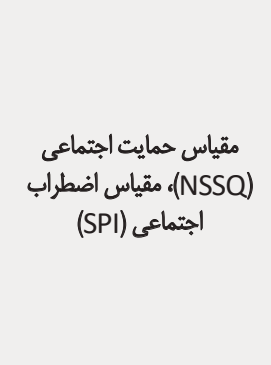 & 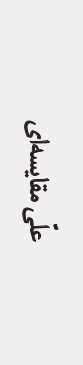 & الصفهان & $\begin{array}{l}\xi_{8} \\
E_{*}\end{array}$ & 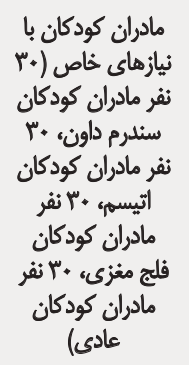 & 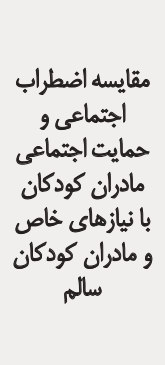 & 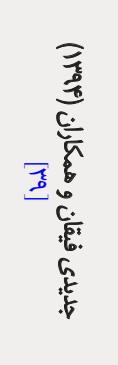 & ir \\
\hline 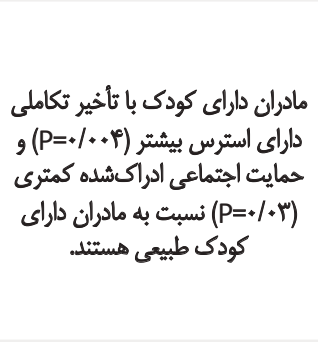 & 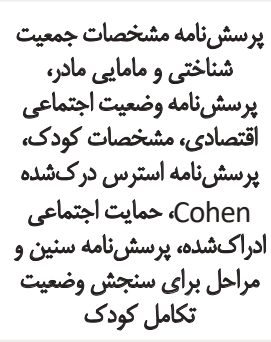 & $\frac{h}{\xi^{k}}$ & تهبران & 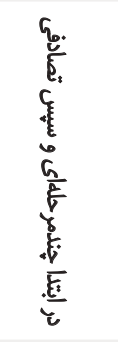 & 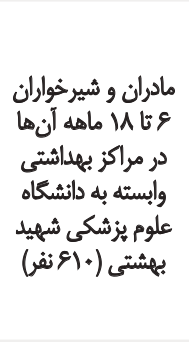 & 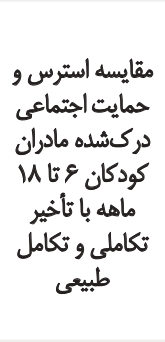 & 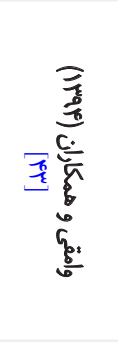 & ir \\
\hline 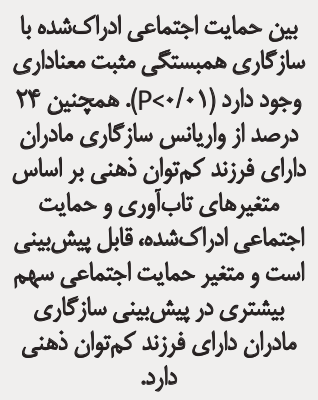 & 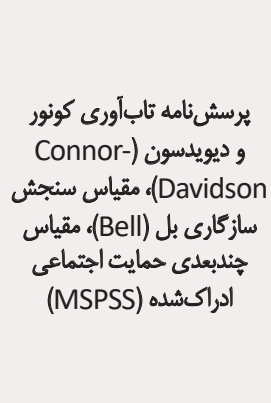 & 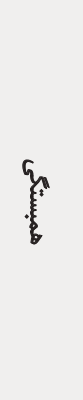 & رشت & $\frac{\xi}{\xi}$ & 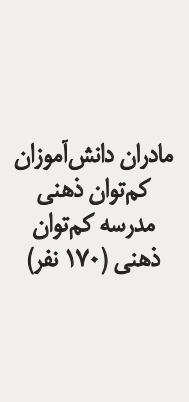 & 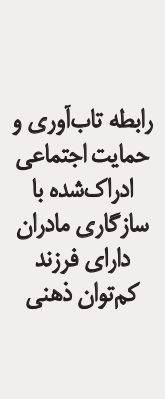 & 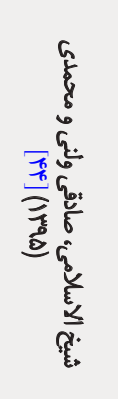 & if \\
\hline
\end{tabular}

$$
\text { حمايت اجتماعى ادراكشده سار اسون و همكار ان }
$$

براى سنجش حمايت اجتماعى از يرسشنامها داره حمايت

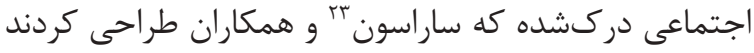

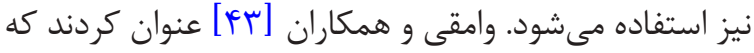

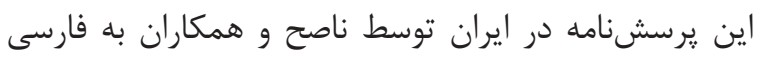

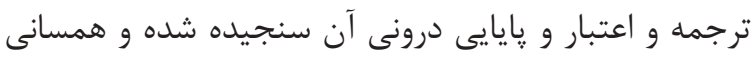

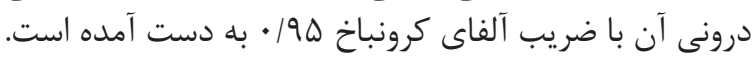

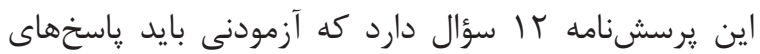

23. Sarason
به دست آوردن امتياز مربوط به هر زيرمقياس كافى است نمرات

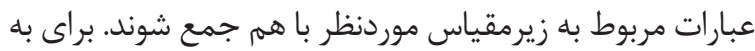

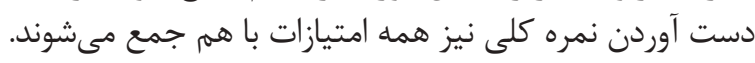

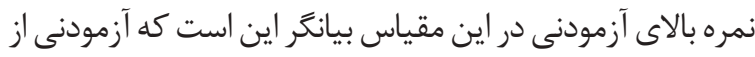

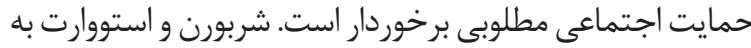

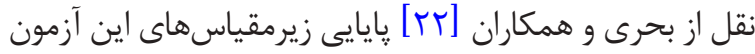

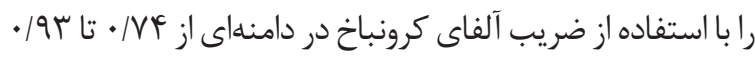

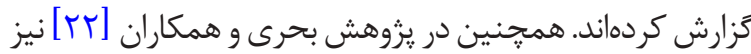

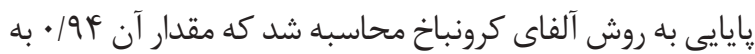

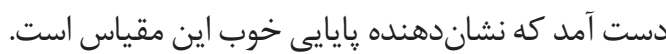


روابط و متغير هاى بررسى شده

در ميان مطالعاتى كه حمايت اجتماعى والد/ والدين كودكان دجار ناتوانى و معلوليت را بررسى كرده بودند، در هفت مطالعاته

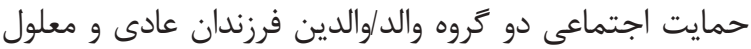

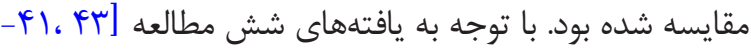

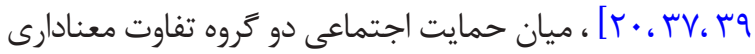

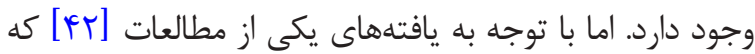

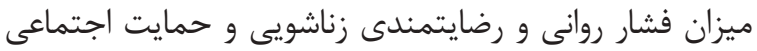

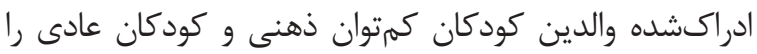
در استان كلستان مقايسه كرده بود، ميان حمايت اجتماعى ذونى ذونى

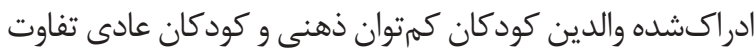

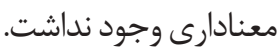

مطالعات به بررسى رابطه ميان حمايت اجتماعى با متغيرهاى

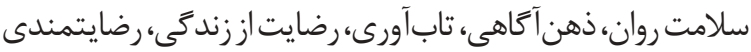

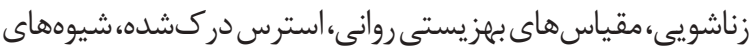

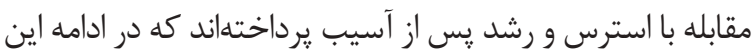
مطالعات و يافتههاى آنان شرح داده مئش بشود.

سه مطالعه رابطه حمايت اجتماعى و سلامت روان را در والدين

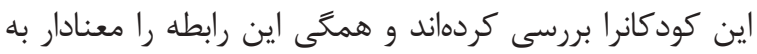

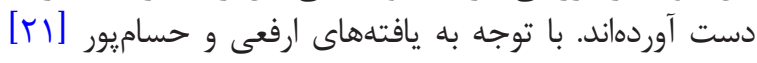

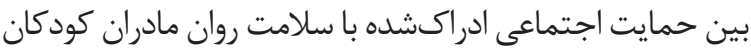

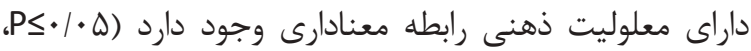

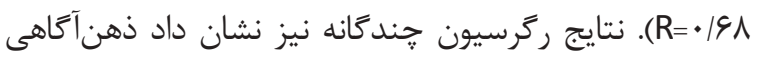

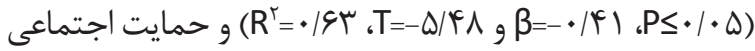
ادراكشده (ه ) (

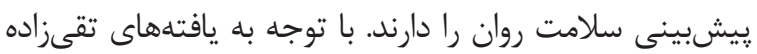

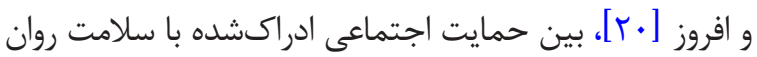

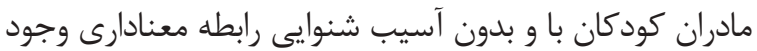

خود را در مقياسٍ هفتدرجهاى ليكرت از لاكاملاً مخالفهم:

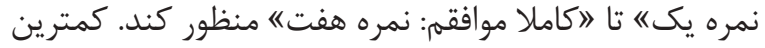

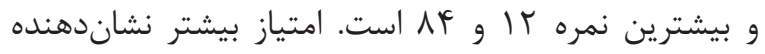
حمايت اجتماعى بالاتر است. در مطالعه وامقى و ورئ همكاران

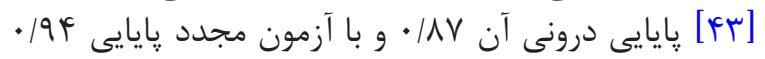

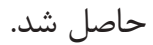

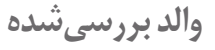

Fاع درصد از مطالعاتى كه به حمايت اجتماعى والدين كودكان

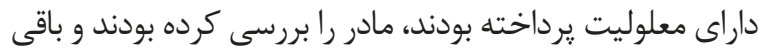
مقالات به مطالعه هر دو والد اقدام كرده بودند.

نوع معلوليت كودى

همان طور كه در جدول شماره r ملاحظه مىشود، در مقالات

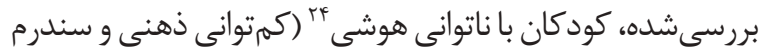

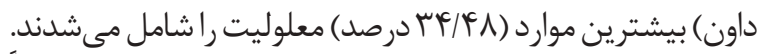

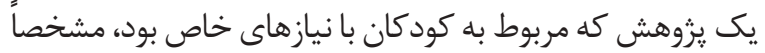

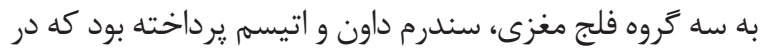

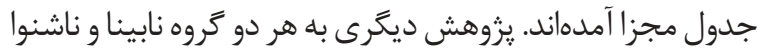

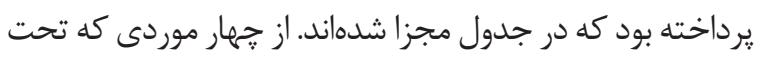
عنوان كودكان استثنايى معرفى شده بودند

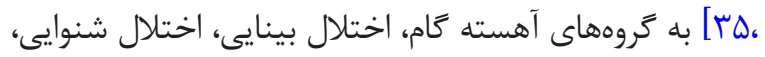

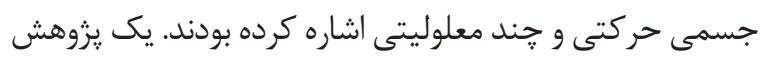

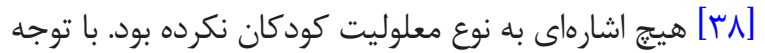

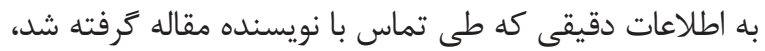
نوع معلوليت در اختيار نويسند

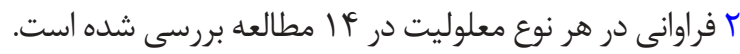

\section{Intellectual disability}

جدول r. فراوائى انواع معلوليت كودكان در If مقاله مطالعهشده

\begin{tabular}{|c|c|c|}
\hline ورحد فراوانى & فراواتئ & نوع معلوليت كودى \\
\hline meres & 1. & ثاثواني هوشى \\
\hline IV/TE & $\Delta$ & اخحتالالات شُوايع \\
\hline IV/TF & $\Delta$ & اختمالات جسمى حركتى \\
\hline $1 r / M$ & r & اختلالات بينايى \\
\hline $1 . / 45$ & $r$ & جناخمعلوليتى \\
\hline$m / M F$ & 1 & اتئيسم \\
\hline$\mu / \mu \varphi$ & 1 & اختلال تكاملى \\
\hline $1 .$. & rq & مجموع نوع معلوليتهاي بررسىشله \\
\hline
\end{tabular}




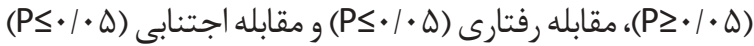

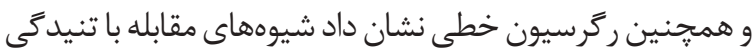
مادران كودكان استثنايى توسط متغير هان

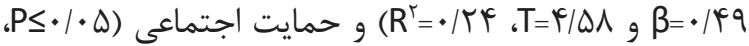

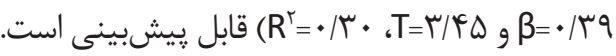

غبارى بناب و همكاران [rه] رابطه ميان حمايت اجتماعى

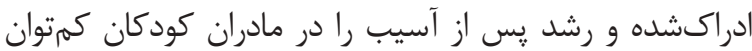

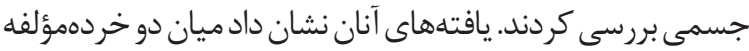

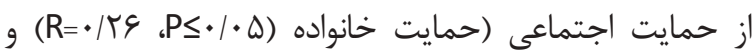

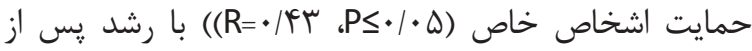

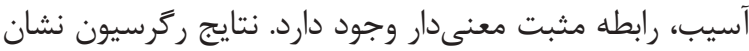

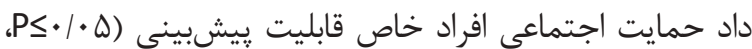

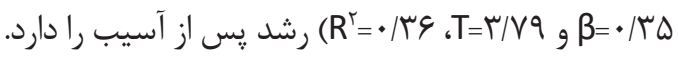

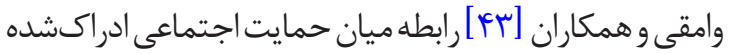

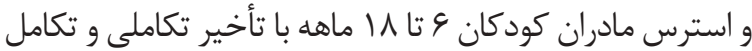

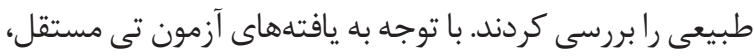

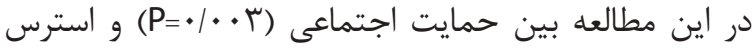

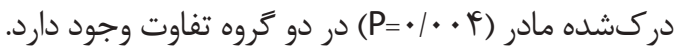

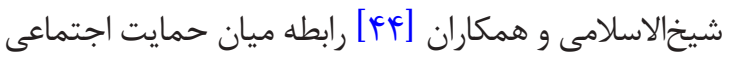

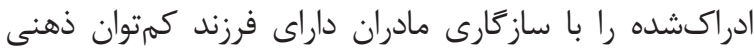

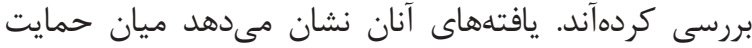

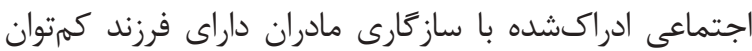

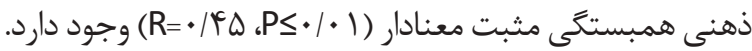

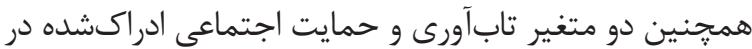

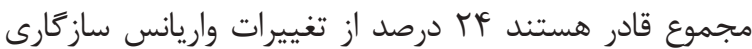

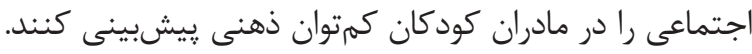

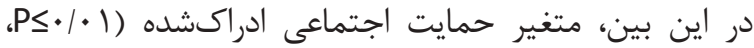

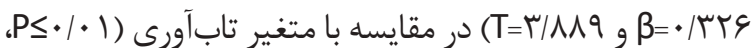

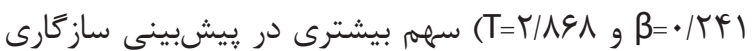

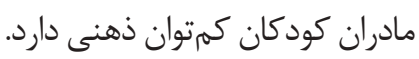

بحث

همانطور كه در يافتهها عنوان شد، در سالهاى اخير موضوع

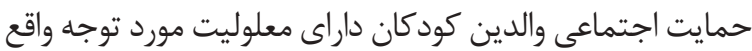

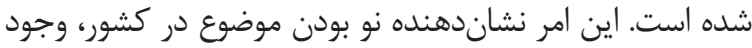

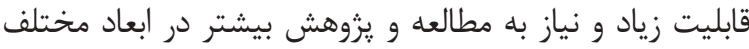

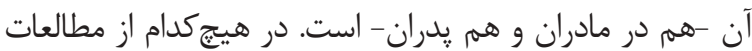

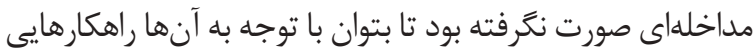

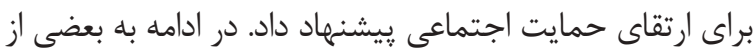

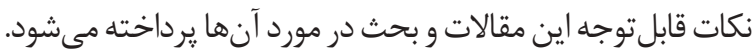

يكى از نكات قابلتوجه در بررسى مطالعات موجود، تمركز

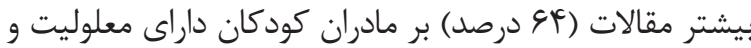

دارد. حمايت اجتماعى ادراكشده مىتواند تغييرات سلامت روان

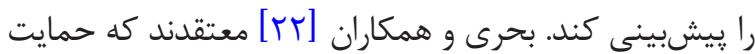

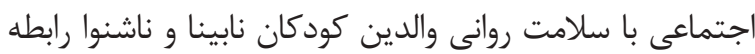

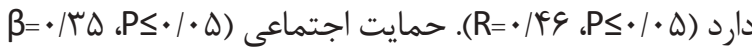

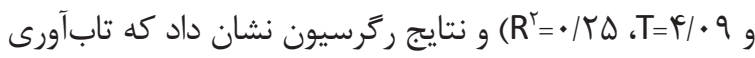

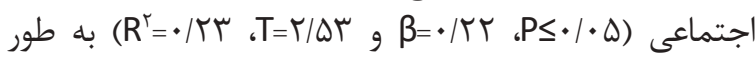

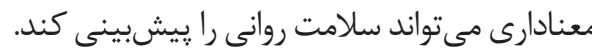
در مطالعه ارفعى و حساميور [آ [ب] رابطه ميان حمايت اجتماعى

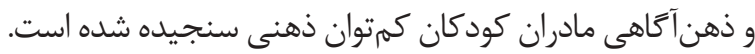

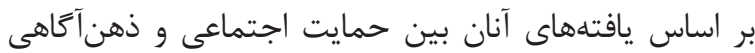

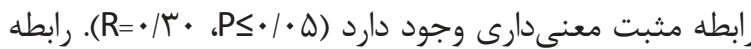

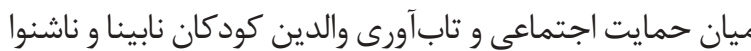

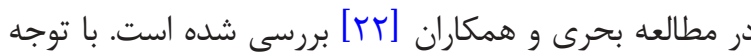

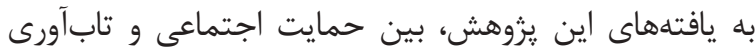

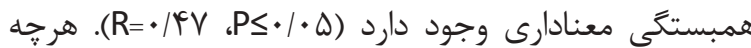

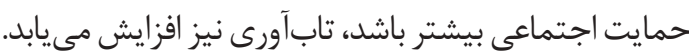
نريمانى و همكاران [عب] رابطه ميان حمايت اجتماعى وكان ورضايت

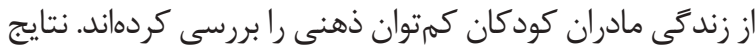

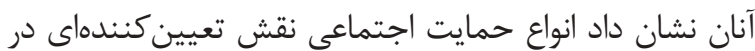

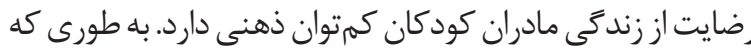

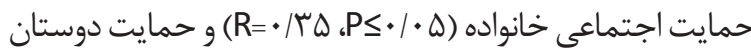

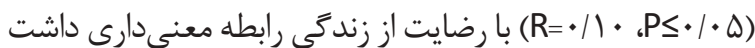

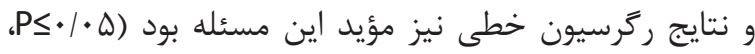
$\left(R^{r}=\cdot / r \cdot T=r / r, \beta=\cdot / \uparrow 99\right.$

ارجمندنيا و همكاران [Fr] رابطه ميان حمايت اجتماعى

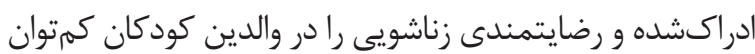

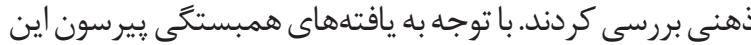

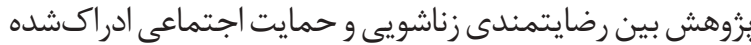

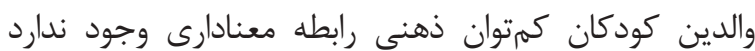

. $(R=\cdot / \Gamma ، P \geq \cdot / \cdot \Delta)$

كاكابرايى و همكاران [ـآ] رابطه ميان حمايت اجتماعى

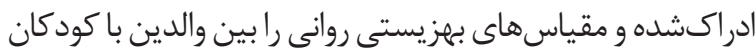

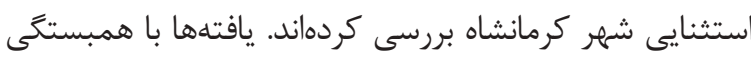

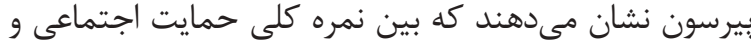

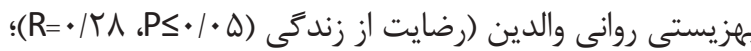

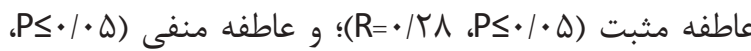
(R=-•/r.

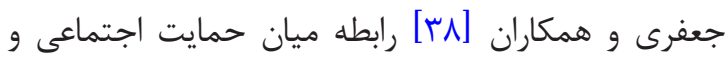

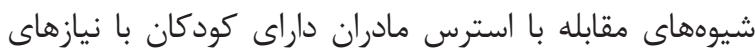

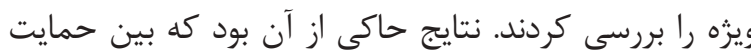

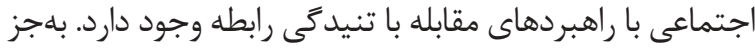

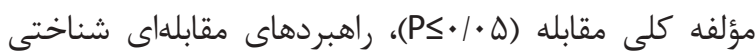




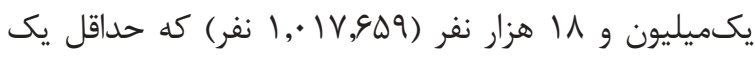

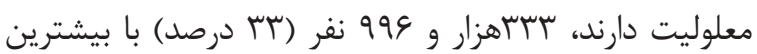

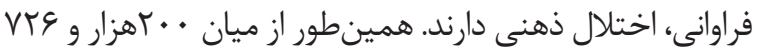

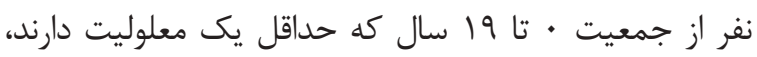

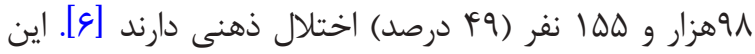

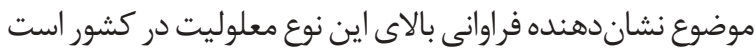

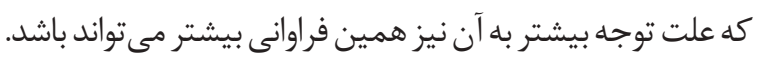

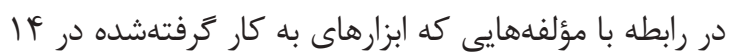
مطالعه يافتشده رامىسنجند مى توان به موارد زير اشاره كرد:

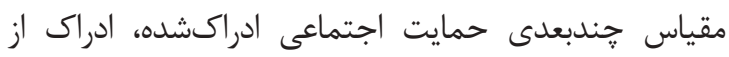

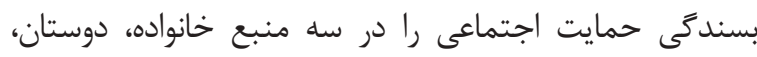

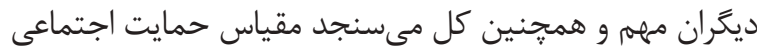

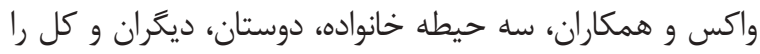

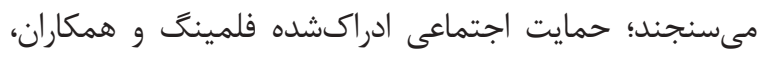

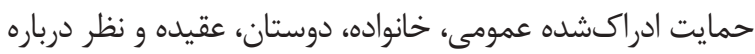

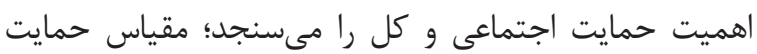

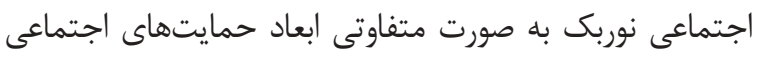

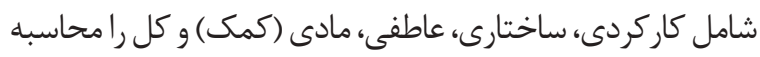

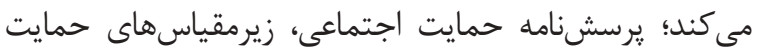

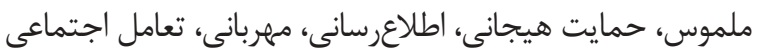

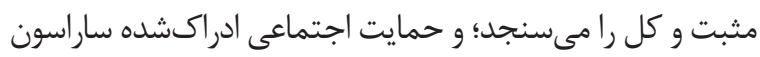

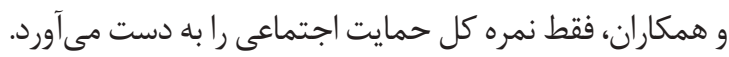
با توجه به تعدد و تفاوت در ابعاد و زيرمقياسهاى ابناى ابزارهاى

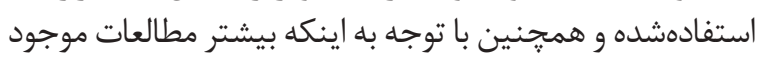

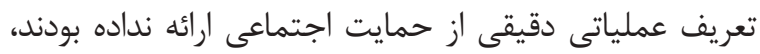

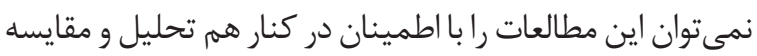

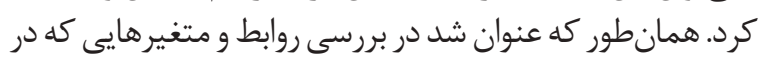

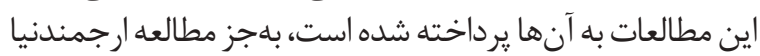

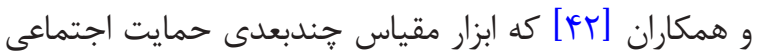

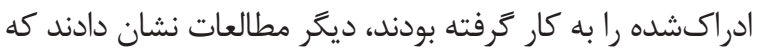

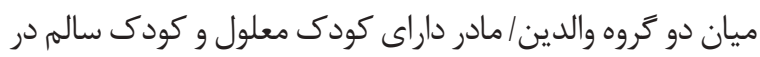

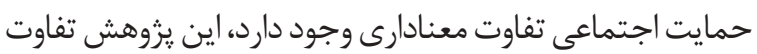

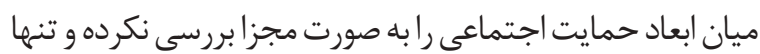

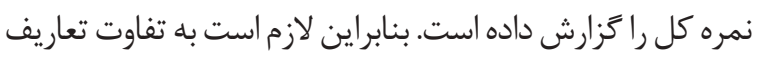
عملياتى اين ابزارها در مقايسه قطعى نتايج توجه شودا لناري

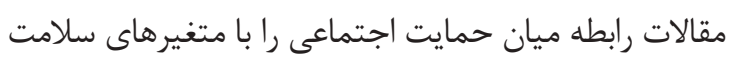

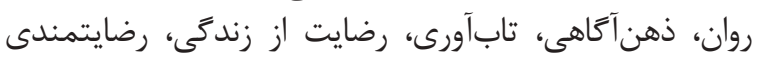

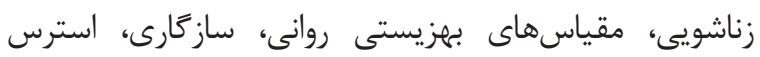

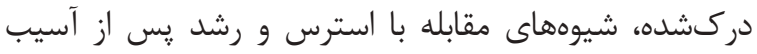

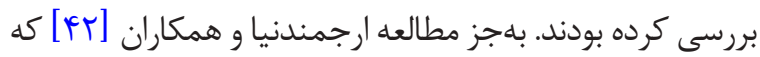

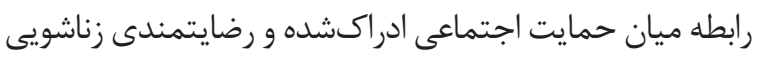
در والدين كودكان كمتوان ذهنى را بررسى كرده و نشان داده
عدم توجه به نقش يدر به صورت مشخص و مجزا است. مطالعاتى

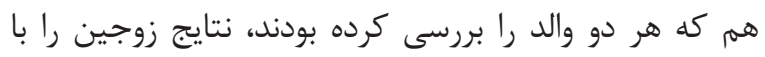

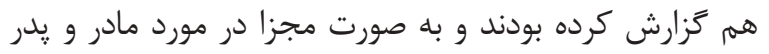

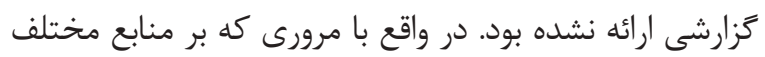

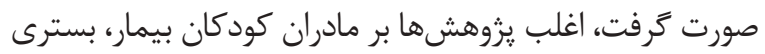

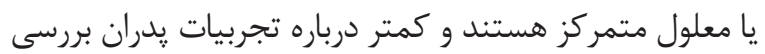

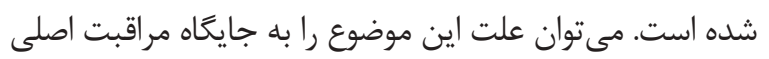

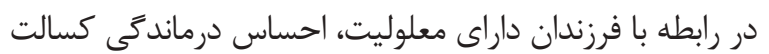

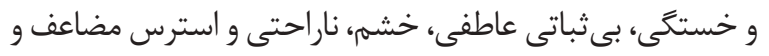

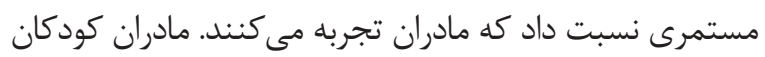

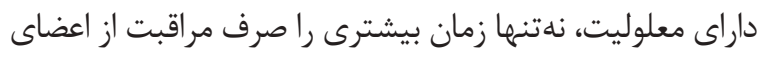

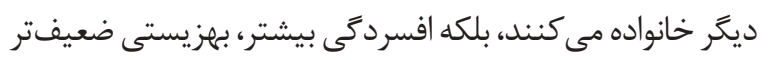

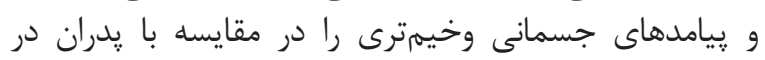

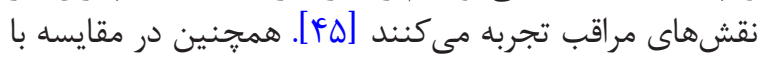

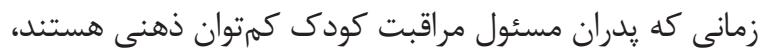

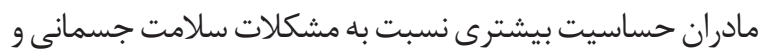

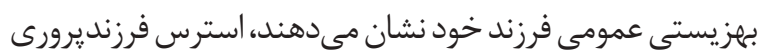

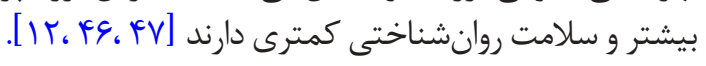
امروزه يدران نسبت به كذشته در زند بحى روزمره كودكانشان

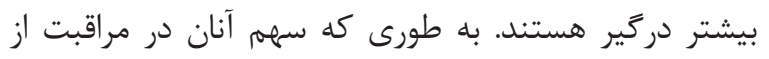

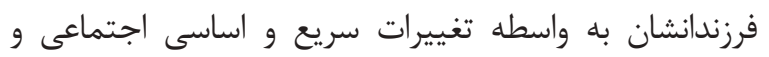

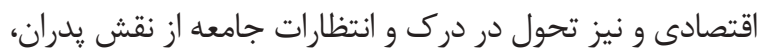

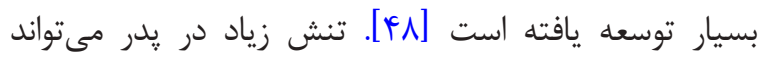

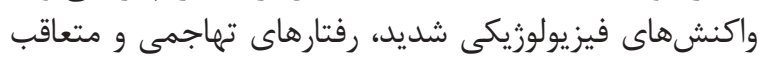

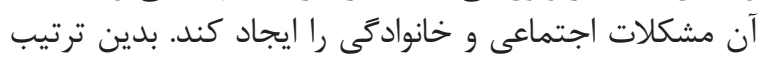

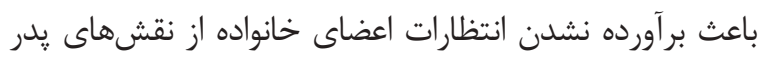

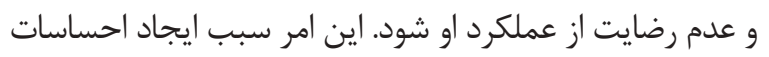

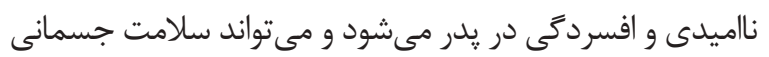

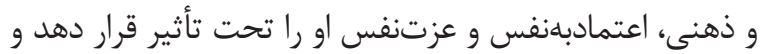

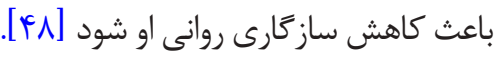

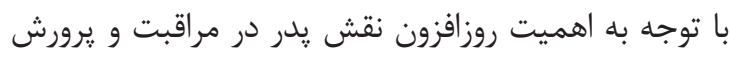

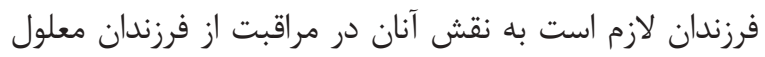

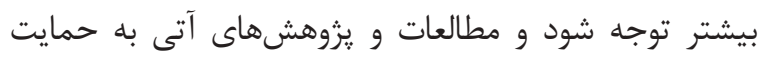
اجتماعى هر دو والد و حتى مقايسه آن دو با هم توجه كنيند.

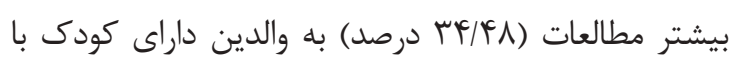

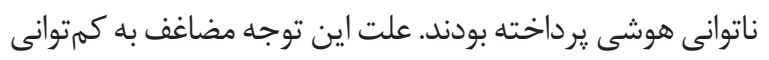

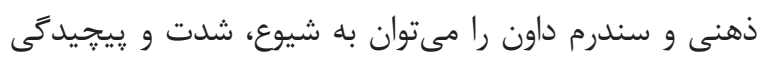

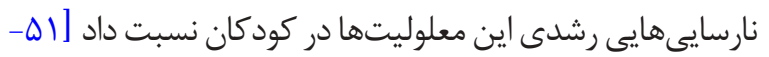

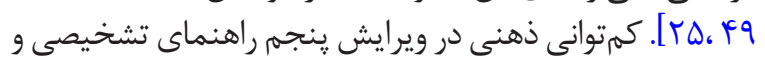

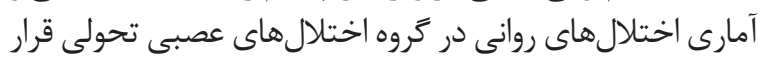

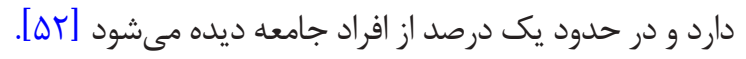

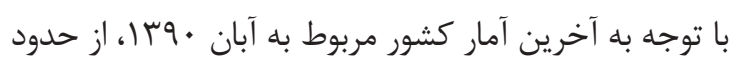


كمكها و خدمات رسمى ارائهده توسط بيمارستانها و مراكز

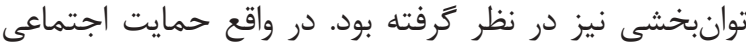

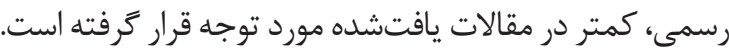

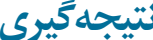

با توجه به موارد مطرحشده كه در رابطه با تأثير حمايت

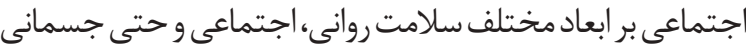

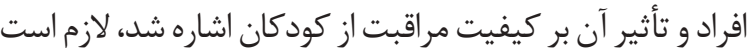

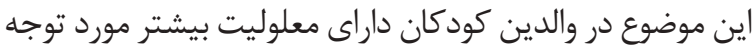

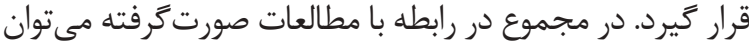

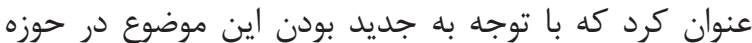

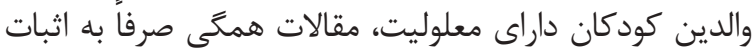

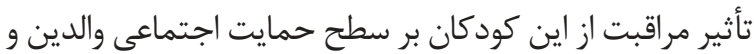

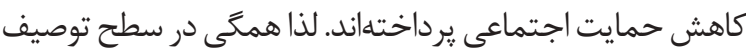

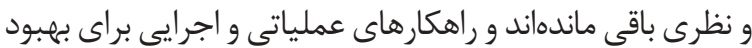

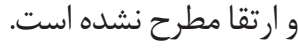

اين مطالعه با اين هدف صورت كرفته است كه طى مرور

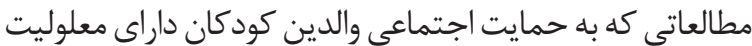

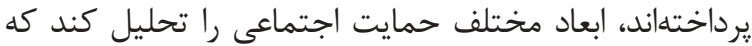

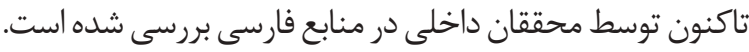

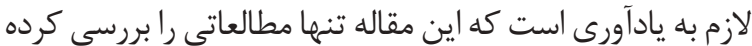

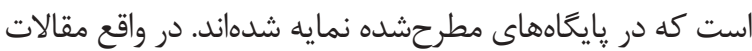

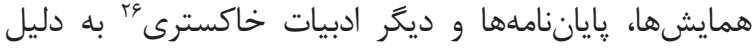

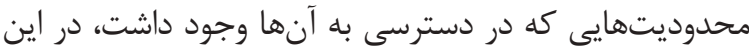

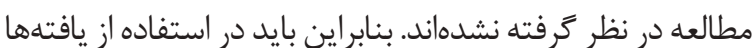
به اين نكته توجه شود.

از طرف ديكر با توجه به محدوديتهايى كه جستوجوى

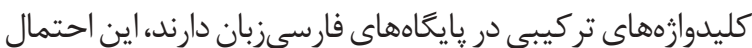

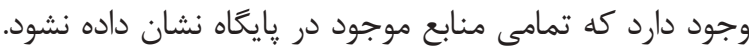

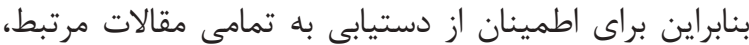

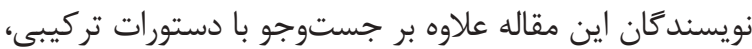

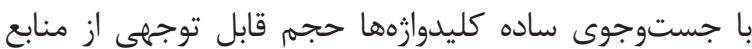
يافتشده را به صورت دستى بررسى كردند.

يافتههاى حاصل از مقالات مى تواند در توسعه و تقويت خدمات

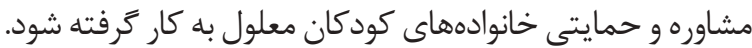

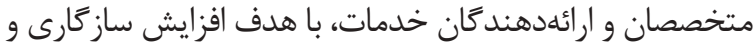

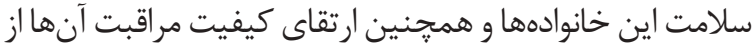

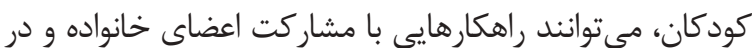

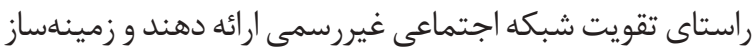

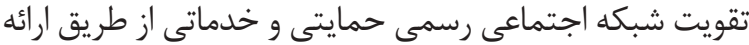
خدمات همه جانبه تيمى باشند.
بود كه بين رضايتمندى زناشويى و حمايت اجتماعى ادراكشده

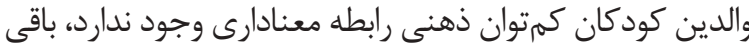

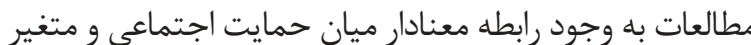
مطالعهشده ديخر دست يافتهاند.

در تأييد اين نتايج، همانطور كه عنوان شد مطالعه هالستيد

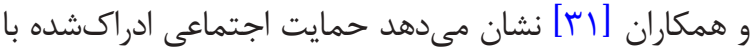

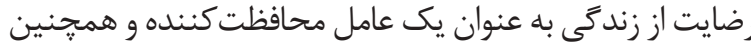

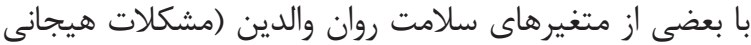

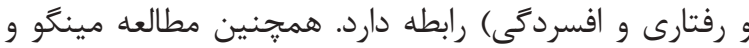

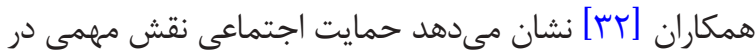

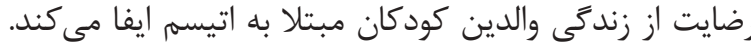

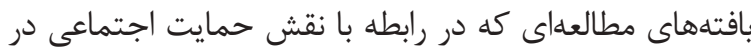

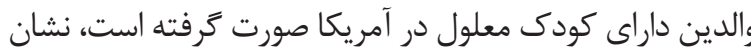

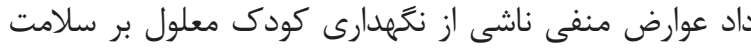

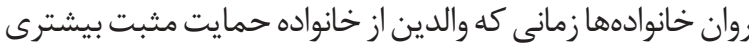

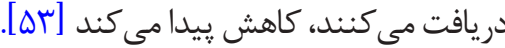

در كره جنوبى مطالعهاى متغيرهاى مختلفى را كه بر كيفيت

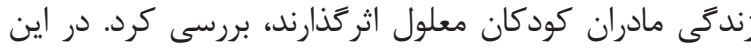

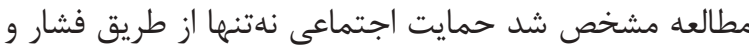

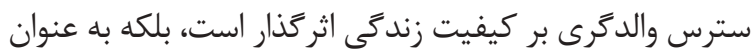

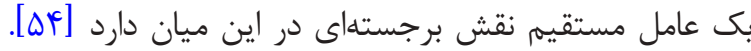

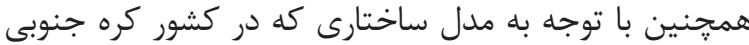

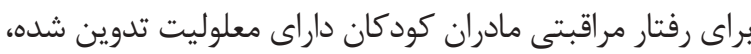

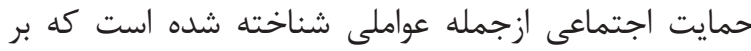

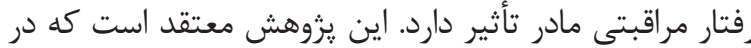

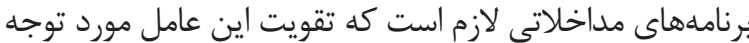

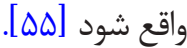

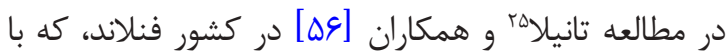

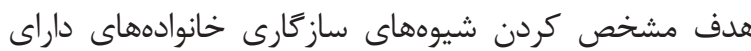

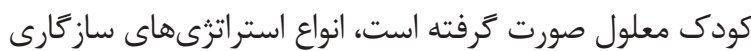

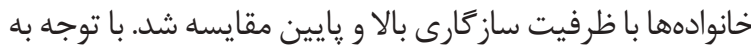

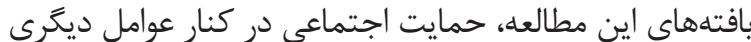

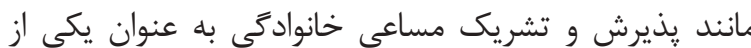

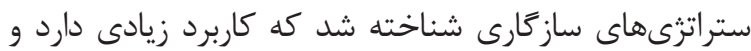

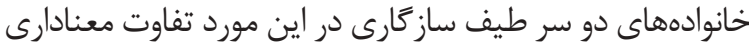

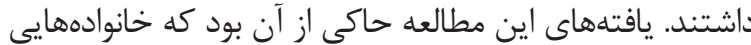

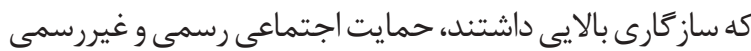

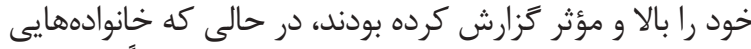

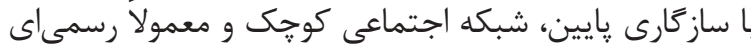

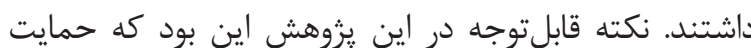

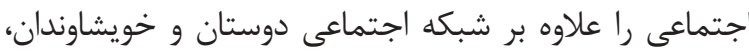


درنهايت با توجه به نكات مطرحشده، وِيشنهاد مىشود

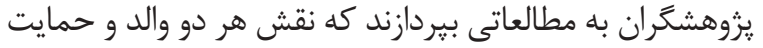

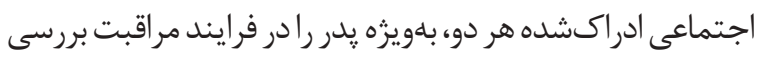

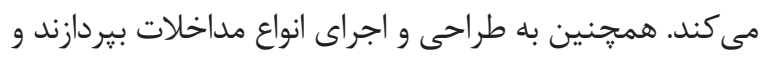

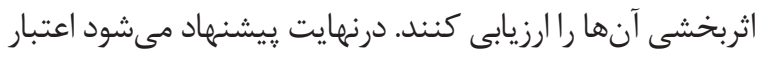

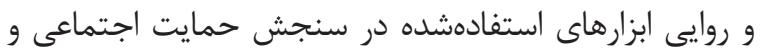

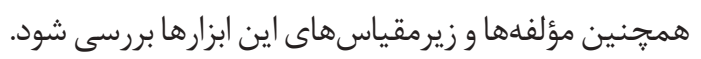

$$
\text { تشكر و قدردانى }
$$

مقاله حامى مالى نداشته است. 


\section{References}

[1] World Health Organization. Constitution of WHO: Principles of 1948. Geneva: World Health Organization; 2006

[2] World Health Organization. International classification of function, disability and health [Statistics Center of Iran, Persian trans.]. Tehran: Statistics Center of Iran Publication; 2016.

[3] Davarmanesh A, Barati Sadeh F. [An introduction to the rehabilitation principles of the disabled (Persian)]. Tehran: Roshd; 2006.

[4] World Health Organization. International classification of functioning, disability and health ICF. Geneva: World Health Organization; 2001.

[5] World Health Organization. World report on disability. Geneva: World Health Organization; 2011

[6] Statistics Center of Iran. [Country statistical journal (Persian)]. Tehran: Statistics Center of Iran; 2015.

[7] Dash M. Education of exceptional children. New Delhi: Atlantic Publishers \& Distributors; 2005.

[8] National Center for Learning Disabilities. IDEA Parent Guide: A Comprehensive Guide to Your Rights and Responsibilities under the Individuals with Disabilities Education Act (IDEA 2004). New York: National Center for Learning Disabilities; 2006.

[9] Exceptional Education Organization of Iran. [History of Exceptional Education Organization of Iran (Persian)]. Tehran: Exceptional Education Organization of Iran; 2000.

[10] Baker BL, Blacher J, Olsson MB. Preschool children with and without developmental delay: Behaviour problems, parents' optimism and well-being. Journal of Intellectual Disability Research. 2005; 49(8):575-90. [DOI:10.1111/j.1365-2788.2005.00691.x] [PMID]

[11] Hogan DP. Family consequences of children's disabilities. New York: Russell Sage Foundation; 2012.

[12] Mohammad Aminzadeh D, Kazemian S, Esmaeily M, Asmari Y. Prediction of perceived empathy based on emotional schemas and resilience in mothers with physically-disabled children. Archives of Rehabilitation. 2017; 18(2):138-49. [DOI:10.21859/jrehab-180138]

[13] Lima MBS, Cardoso VdS, Silva SSdC. Parental stress and social support of caregivers of children with cerebral palsy. Paidéia (Ribeirão Preto). 2016; 26:207-14. [DOI:10.1590/1982-43272664201608]

[14] Dantas MSdA, Pontes JF, Assis WDd, Collet N. [Family difficulties and difficulties in caring for children with cerebral palsy (Portuguese)]. Journal of Nursing. 2012; 33:73-80. [DOI:10.1590/S198314472012000300010]

[15] Cobb S. Social support as a moderator of life stress. Psychosomatic Medicine. 1976; 38(5):300-14. [DOI:10.1097/00006842197609000-00003] [PMID]

[16] Musavinasab M, Ravanipour M, Pouladi S, Motamed N, Barekat M. [Validity and reliability of elderly patients with cardiovascular disease empowerment questionnaire in receiving social support (Persian)]. Iranian Journal of Ageing. 2016; 11(2):258-69. [DOI:10.21859/sija-1102258]

[17] Helgeson V. Social support and quality of life. Quality Of Life Research. 2003; 12:25-31. [DOI:10.1023/A:1023509117524] [PMID]
[18] Nosratabadi M, Sadeghi R, Halvaiepour Z. [Exploring the relationship between social capitals, and social support with mother's health in mothers referring to health centers of Sirjan City: A structural model (Persian)]. The Journal of Urmia Nursing and Midwifery Faculty. 2015; 13(9):781-90.

[19] Atadokht A, Jokar Kamalabadi N, Hosseini Kiasari T, Bashar-Pour $\mathrm{S}$. [The role of perceived social support in predicting psychological disorders in people with physical disability and its comparison with normal subjects (Persian)]. Archives of Rehabilitation. 2014; 15(3):26-36.

[20] Taghizadeh H, Afrooz Q. [Comparison of perceived social sup port and mental health of mothers of children with and without hearing-impairment (Persian)]. Journal of Exceptional Education. 2014; 2(124):7-17.

[21] Sedighi Arfaee F, Hesampour F. [The relationship between mindfulness and perceived social support and mental health in mothers of children with intellectual disability (Persian)]. Quarterly Journal of Social Work. 2016; 4(4):42-52

[22] Bahri SL, Dehghan M, Dehghan Z. [To investigating the role of predictability of resilience and social support in mental health of blind and deaf children parents (Persian)]. Journal of Exceptional Education. 2014; 14(1):5-12.

[23] Kerenhappuch MS, Sridevi G. Caregiver burden and social sup port: Mothers of children with mental retardation. Saarbrücken: Lap Lambert Academic Publishing; 2014

[24] Bakhtiyari M, Emaminaeini M, Hatami H, Khodakarim S, Sahaf R. [Depression and perceived social support in the elderly (Persian)]. Iranian Journal of Ageing. 2017; 12(2):192-207.

[25] Ghobari B. B, Rafikhah M, Mohajerani M. Relationship between attachment to God and perceived social support with post-traumatic development in mothers of children with physical disability (Persian)]. Journal of Psychology Achievements. 2014; 21(1):1-14.

[26] Robinson S, Weiss JA, Lunsky Y, Ouellette-Kuntz H. Informa support and burden among parents of adults with intellectual and/ or developmental disabilities. Journal of Applied Research in Intellectual Disabilities. 2016; 29(4):356-65. [DOI:10.1111/jar.12184] [PMID]

[27] Kissel SD, Nelson WM. Parents' perceptions of the severity of their child's autistic behaviors and differences in parental stress, family functioning, and social support. Focus on $\mathrm{Au}-$ tism and Other Developmental Disabilities. 2016; 31(2):152-60. [DOI:10.1177/1088357614537352]

[28] Gerstein ED, Crnic KA, Blacher JJ, Baker BL. Resilience and the course of daily parenting stress in families of young children with intellectual disabilities. Journal of Intellectual Disability Research. 2009; 53:981-97. [DOI:10.1111/j.1365-2788.2009.01220.x] [PMID] [PMCID]

[29] Knestrict T, Kuchey D. Welcome to Holland: Characteristics of resilient families raising children with severe disabilities. Journal of Family Studies. 2009; 15:227-44. [DOI:10.5172/jfs.15.3.227]

[30] Parish SL, Rose RA, Andrews ME. TANF's impact on low-income mothers raising children with disabilities. Exceptional Children. 2010; 76:234-53. [DOI:10.1177/001440291007600206] 
[31] Halstead EJ, Griffith GM, Hastings RP. Social support, coping, and positive perceptions as potential protective factors for the wellbeing of mothers of children with intellectual and developmental disabilities. International Journal of Developmental Disabilities. 2017; 1-9. [DOI:10.1080/20473869.2017.1329192]

[32] Minghui L, Guangxue Y, Skora E, Guanghai W, Yandong C, Qingzhou S, et al. Self-esteem, social support and life satisfaction in Chinese parents of children with autism spectrum disorder. Research in Autism Spectrum Disorders. 2015; 17:70-7. [DOI:10.1016/j. rasd.2015.05.003]

[33] Babbie E. The practice of social research. Belmont: Wadsworth Thomson Learning; 2001. [PMID]

[34] Sajadi H, Mohaqeqi Kamal H, Vameghi M, Forozan AS, Rafei H, Nosratabadi M. [Systematic review of prevalence and risk factors associated with depression and its treatment in Iranian elderly (Persian)]. Iranian Journal of Ageing. 2013; 7(4):7-15.

[35] Kakabaraei K, Arjmandnia AA, Afrooz GA. [The relationship between coping strategies and perceived social support and mental well-being scales in parents with exceptional and normal children in Kermanshah, in 2010 (Persian)]. Psychology of Exceptional Individuals. 2012; 2(7):1-26.

[36] Narimani M, Rostami M. [Role of religious attitudes, spiritual well-being and social support in predicting the life satisfaction in mothers of mental retardation children (Persian)]. Islam and Health Journal. 2014; 1(3):41-9.

[37] Naderi F, Safarzadeh S, Roya M. [Comparison of self-sickness, social support, social anxiety and general health among mothers with mentally retarded and normal children (Persian)]. Health and Psychology. 2011; 1(1):17-40.

[38] Jafari E Esmaeili A, Atadokht A.[The relationship between religiosity and social support with coping styles in the mothers of children with special needs (Persian)]. Psychology of Exceptional Individuals. 2015; 5(18) :89-99. [DOI: 10.22054/JPE.2015.1546]

[39] Jadidi M, Safary S, Jadidi M, Jamali S. [Comparing social support and social anxiety between mothers of children with special needs and mothers of normal children (Persian)]. Knowledge \& Research in Applied Psychology. 2015; 16(2):43-52.

[40] Kakabaraei K, Afrooz GA, Heidar Ali H, Moradi AR. [Investigation and comparison of the mental wellbeing, coping styles and Perceived Social Support in Parents having exceptional and normal children (Persian)]. Journal of Research in Psychological Health. 2011; 5(2):45-58.

[41] Kakabaraei K, Arjmandnia AA, Afrooz GA. [Comparison of perceived social support in parents with more than one exceptional children and parents with more than one normal children (Persian)]. Social Psychology Research Quarterly. 2012; 2(8):13-18.

[42] Arjmand Nia AA, Afrooz G, Nami MS. [The comparison between marital satisfaction, emotional stress cognitive social support in parents having mentally-impaired children and parents having normal children (Persian)]. Journal of Exceptional Education. 2013; 13(116):5-15.

[43] Vameghi R, Amir Aliakbari S, Sajedi F, Sajjadi H, Alavimajd H, Hajighasemali S. [Comparison of stress and perceived social support in mothers of 6-18 month-old children with and without developmental delay (Persian)]. Journal of Hayat. 2015;21(3):74-87.
[44] Sheikh Eslami A, Sadeghi Valani Z, Mohmmadi N. [The relationship of resiliency and perceived social support with adjustment of mothers with intellectually disable child (Persian)]. Psychology of Exceptional Individuals. 2015; 6(21):141-55.

[45] Valizadeh S, Davoudi Far A, Berdi Ozouni Davaji R, Alaee Z. [Effectiveness of group coping skills training on reducing stress and hopelessness in mothers of children with intellectual disabilities (Persian)]. Journal of Exceptional Children. 2010; 10(3):237-44.

[46] Narimani M, Agha Mohammadian Sherbaf HR, Rajabi S. [Comparison of mental health of exceptional children mothers with mothers of normal children (Persian)]. Fundamentals of Mental Health. 2007; 9(33-34):15-24.

[47] Kimiaie SA, Mehrabi B. H, Mirzai Z. [Comparison of mental health status of fathers and mothers of mentally retarded children in Mashhad (Persian)]. Studies of Training and Psychology. 2010; 11(1):261-78.

[48] Ghaderi S, Alaee Karahrudi F, Yousefi Chaijan P, Nasiri Oscui N. [Fathers-participation in the care of hospitalized child in pediatric intensive care unit on fathers-stress and coping strategies (Persian)] Arak Medical University Journal. 2014; 16(10):61-9.

[49] Bayrami M, Hassimi Nosratabad T, Besharat R, Movahedi Y, Kohpayma S. [The study of the components of neuroticism among parents of autistic children, mental retarded and normal in the city of Tabriz (Persian)]. Journal of Exceptional Education. 2013; 9(122):17-27.

[50] Myrbakk E, Tetzchner SV. Psychiatric disorders and behavior problems in people with intellectual disability. Research in Developmental Disabilities. 2008; 29:316-32. [DOI:10.1016/j. ridd.2007.06.002] [PMID]

[51] Nesayan A, Asadi Gandomani R. [Effectiveness of social skills training on behavioral problems in adolescents with intellectual disability (Persian)]. Archives of Rehabilitation. 2016; 17(2):158-67. [DOI:10.21859/jrehab-1702158]

[52] Ghotbzadeh Asrar F, Shakerinia I. [The relationship between parenting styles with adaptive behavior among students with intellectuall disability (Persian)]. Quarterly Journal of Child Mental Health. 2015; 2(3):49-58.

[53] Ha JH, S Greenberg J, Mailick M. Parenting a child with a disability: The role of social support for African American parents. The Journal of Contemporary Social Services. 2011; 92(4):405-11. [DOI:10.1606/1044-3894.4150] [PMID] [PMCID]

[54] Seu Cho K, Joo Hong E. A Path analysis of the variables related to the quality of life of mothers with disabled children in Korea. Stress \& Health Journal of the International Society for the Investigation of Stress. 2013; 29(3):229-39 [DOI:10.1002/smi.2457] [PMID]

[55] Lee AR. A structural model of caring behavior of mothers of disabled children. Journal of Korean Academy of Nursing. 2009; 39(5):673-82. [DOI:10.4040/jkan.2009.39.5.673] [PMID]

[56] Taanila A, Syrjälä L, Kokkonen J, Järvelin MR. Coping of parents with physically and/or intellectually disabled children. Child: Care, Health \& Development. 2002; 28(1):73-86. [DOI:10.1046/j.13652214.2002.00244.x] 